\title{
Escutar os mortos com os ouvidos. Dilemas historiográficos: os sons, as escutas e a música
}

José Geraldo Vinci de Moraes ${ }^{1 *}$

\section{RESUMO}

"Escutar os mortos" é uma preocupação presente já no surgimento da história como conhecimento do passado. A historiografia, desde sua tradição helênica, criou um universo teórico de "escutá-los com os olhos" e uma prática metodológica de "ouvir com os olhos". Nesta longa trajetória, a escuta do mundo e dos homens tornou-se secundária diante da presença hegemônica do olhar, da escrita e da leitura. Porém, na segunda metade do século XIX essa relação se alterou profundamente, principalmente com o surgimento dos registros mecânicos e depois eletrônicos dos sons, a possibilidade de sua reprodução para além do momento da criação e emissão original e com o aparecimento das inúmeras possibilidades de sua propagação a distância. Essa virada auditiva rapidamente se integrou à vida cotidiana do homem contemporâneo, tornou-se preocupação de alguns campos do conhecimento, mas permaneceu distante da historiografia. Só mais atualmente a historiografia tem se preocupado em "escutar os mortos" e o passado com seus próprios "ouvidos" e se questionado sobre como escutá-los com "ouvidos emprestados". Este artigo pretende justamente discutir aspectos dessa trajetória e introduzir questôes e alguns dilemas historiográficos relacionados ao universo dos sons, das escutas e da música.

Palavra-chave: historiografia; historiadores; escuta; sons; música.

\section{Listening to the Dead with the Ears. Historiographical Dilemmas: Sound, Listening and Music}

\section{ABSTRACT}

"Listening to the dead" has been a concern since the emergence of history as knowledge of the past. Ever since its Helenic tradition, historiography has created a theoretical

DOI: http://dx.doi.org/10.1590/2237-101X01903805

Artigo recebido em 15 de maio de 2017 e aprovado para a publicação em 4 de outubro de 2017. A pesquisa de base para esse artigo contou com a auxílio do CnpQ, bolsa PQ, e da Fapesp, bolsa BPEx.

${ }^{1}$ Universidade de São Paulo, São Paulo, São Paulo, Brasil.

* Professor da Universidade de São Paulo. E-mail: zgeraldo@usp.br. 
universe of "listening to them with the eyes", and a methodological practice of "listening with the eyes". In this long trajectory, listening to the world and to men has become secondary in the face of the hegemonic presence of looking, writing and reading. However, in the second half of the $19^{\text {th }}$ Century, this relationship changed profoundly, mainly due to the emergence of the mechanical and later electronic recording of sound, the possibility of its reproduction long after the original creation and emission, and due to the appearance of numerous possibilities of long-distance sound propagation. This auditory turn was quickly integrated into the everyday lives of contemporary men, became a concern of some fields of knowledge, but remained ignored by historiography. Not until recently has historiography become concerned with "listening to the dead" and to the past with its own "ears", and asked itself how to listen to them with "borrowed ears". This article seeks specifically to discuss aspects of this trajectory and to introduce issues/questions and historiographical dilemmas related to the universe of sound, listening and music.

Keywords: historiography; historians; listening; sounds; music.

\section{Escuchar a los muertos con los oídos. Dilemas historiográficos: los sonidos, las escuchas y la música}

\section{RESUMEN}

"Escuchar a los muertos" es una preocupación presente desde el surgimiento de la historia como conocimiento del pasado. La historiografía, desde su tradición helénica, creó un universo teórico de "escucharlos con los ojos" y una práctica metodológica de "oír con los ojos". En esta larga trayectoria, la escucha del mundo y de los hombres se hizo secundaria por la presencia hegemónica de la mirada, de la escritura y de la lectura. Sin embargo, en la segunda mitad del siglo XIX, esa relación se alteró profundamente, principalmente con el surgimiento de los registros mecánicos y después electrónicos de los sonidos, la posibilidad de su reproducción más allá del momento de su creación y emisión original, y con el aparecimiento de inúmeras probabilidades de propagarlo a distancia. Ese cambio auditivo rápidamente se integró a la vida cotidiana del hombre contemporáneo, y se volvió preocupación de algunos campos del conocimiento, pero permaneció distante de la historiografía. Sólo actualmente la historiografía se ha interesado en "escuchar a los muertos" y al pasado con sus propios "oídos", así como también se ha cuestionado sobre cómo escucharlos con los "oídos prestados". Este artículo pretende justamente discutir aspectos de esa trayectoria e introducir cuestiones y algunos dilemas historiográficos relacionados al universo de los sonidos, de las escuchas y de la música.

Palabras clave: historiografía; historiadores; escuchas; sonidos; música. 


\section{Escutar os mortos... com os ouvidos}

\section{Escutar e ver: impasses}

Heráclito de Éfeso (séculos VI-V a. C.) avaliava que para alcançar a verdade das coisas "os olhos eram testemunhas mais exatas que os ouvidos". ${ }^{2}$ Tudo indica que ele ponderava que as sensaçôes advindas da prática verbal, mnemônica e performática não eram dignas de confiança da verdade, como seria a escrita, bem mais relacionada ao mundo visual e, como desdobramento, mais próxima da razão. A dinâmica cultural neste momento era a da lenta construção e relativa expansão de uma tradição letrada. Ocorre que as práticas de escrita e de leitura permaneciam ainda tributárias da cultura oral e a palavra falada predominava evidentemente como linguagem. Mas no mundo vivido por Heráclito começava a ocorrer a substituição gradual da prática poética pela prosa, provavelmente mais adequada para desenvolver narrativas extensas e conceituais, além de permitir o incrível registro permanente e externo da memória. Nessa nova circunstância que se apresentava, as práticas da escrita e da leitura começaram a instituir gradativamente um universo cada vez mais visual, tornando a escuta secundária, reduzindo o ouvido a simplesmente uma espécie de colaborador do olho. ${ }^{3} \mathrm{E}$ nesse passo o mundo da leitura foi interiorizando a voz, tornando-se cada vez mais e necessariamente o universo da quietude e do silêncio externo e interno. ${ }^{4}$

Essa dinâmica cultural foi determinante para a formulação de certa genealogia do pensamento grego que se tornou hegemônica. Apesar da existência de outras tradiçóes e reflexôes, como os casos mais conhecidos do ceticismo e do sofismo, foi essa maneira de pensar o mundo e os homens que gradativamente tornou-se predominante. E certamente ela se apresentou na discussão que se instaurou por volta do século $\mathrm{V}$ a. C., quando teve início a formação de um novo estilo narrativo na forma de prosa, o historiográfico. ${ }^{5} \mathrm{De}$ certo modo pode-se dizer que esse novo gênero literário anunciava o rompimento com as narrativas estritamente poéticas (orais) sobre o passado. ${ }^{6}$ Além disso, a memória a ser

\footnotetext{
${ }^{2}$ HERÁClito DE EFESO. In: Pré-socráticos. Os Pensadores. v. 1. São Paulo: Nova Cultural, p. 61.

${ }^{3}$ HAVELOCK, Erick. A revolução da escrita na Grécia. São Paulo: Unesp/Paz e Terra, 1996, p. 21.

${ }^{4}$ SVENBRO, Jesper. A Grécia arcaica e clássica: a invenção da leitura silenciosa. In: CAVALLO, Guglielmo; CHARTIER, Roger (Org.). História da leitura no mundo ocidental. Sáo Paulo: Ática, 1998, p. 50-57.

${ }^{5}$ MÉIER, Christian. Antiguidade. In: KOSSELECK, Reinhart (Org.). O conceito de história. Belo Horizonte: Autêntica, 2013, p. 43.

${ }^{6}$ Derrida indica criticamente que a história da escritura fonética foi o grande meio de desenvolvimento da grande aventura científica, metafísica, técnica e econômica da cultura ocidental. DERRIDA, Jacques. Gramatologia. São Paulo: Perspectiva, 1973, p. 12. Já Derrick Kerckhove diz que "graças ao programa instalado nas nossas cabeças pelo alfabeto, inventamos o direito, a história (...)”. KERCKHOVE, Derrick. A pele da cultura. Investigando a nova realidade eletrônica. São Paulo: Annablume, 2009, p. 53. (grifo nosso).
} 
preservada não seria mais a oral, mas a materializada pela escrita e rememorada a qualquer momento pelo ato da leitura. ${ }^{7}$ Para o sucesso dessa construção, além da prática do binômio escrita-leitura, foi fundamental também a ideia de que seria possível chegar ao conhecimento e à veracidade dos acontecimentos pretéritos com a investigação e o inquérito daqueles que testemunharam os acontecimentos, escapando das explicações exclusivamente mitológicas e fantasiosas. Consultar diretamente quem presenciou os eventos tornou-se entáo o meio para acessar e preservar o passado do esquecimento e, consequentemente, consolidá-lo para a posteridade. O desdobramento imediato dessa percepção foi converter aquele que viu naquele que sabe, dando contornos ao princípio básico da testemunha, mais especificamente da "testemunha ocular".

Como se sabe, Heródoto de Halicarnasso seguiu exemplarmente esse caminho, bem provavelmente abandonando aos poucos a leitura em voz alta, colaborando também para aprofundar a distinção entre a coisa vista e a coisa ouvida. ${ }^{8}$ Ocorre que, se ver e presenciar diretamente o acontecimento fosse impraticável para o observador, Heródoto indicou a possibilidade metodológica de investigá-lo escutando aquele que o vivenciou. Tucídides, pouco depois, reafirmaria essa mesma prática para recuperar os fatos vistos: "Considerei meu dever relatá-los, não como apurados através de algum informante casual nem como me parecia provável, mas somente após investigar cada detalhe com o maior rigor possível, seja no caso de eventos dos quais eu mesmo participei, seja naqueles a respeito dos quais obtive informaçóes de terceiros"?

Isso significava que quem não viu poderia interrogar aquele que viu. Embora se pudesse sempre recorrer a essas informaçóes recebidas de maneira indireta, ouvidas e repassadas por outro alguém, elas eram discutíveis e sua validade integral questionável. Em primeiro lugar, confiava-se nos próprios olhos, depois nos ouvidos, mas sempre acreditando por princípio no olhar das outras testemunhas. E se o evento já estivesse submerso no passado um tanto longínquo, tornando impossível a existência das testemunhas oculares, as informaçôes poderiam ser vistas por meio de outras mediaçóes, pri-

\footnotetext{
${ }^{7}$ Paul Ricoeur apresenta discussão sobre as relaçôes e tensôes entre imaginação e memória, que desembocaria nas tradiçóes platônicas e aristotélicas. Na primeira, a representação do ausente no tempo presente passaria necessariamente pela via da imaginação; na segunda, a representação já seria dada pela percepção mesma da coisa ocorrida, experimentada e adquirida. RICOEUR, Paul. A memória, a história e o esquecimento. Campinas: Ed. Unicamp, 2007, capítulo 1 da parte I.

${ }^{8}$ MOMIGLIANO, Arnaldo. As raizes clássicas da historiografia moderna. Bauru: EdUsc, p. 59-66.

${ }^{9}$ TUCÍDIDES, História da Guerra do Peloponeso. Tradução do grego de Mário da Gama Kury. 4. ed. Brasília: Editora Universidade de Brasília, Instituto de Pesquisa de Relações Internacionais; São Paulo: Imprensa Oficial do Estado de Sáo Paulo, 2001, I. 22, p. 14 (grifo nosso). Sobre essa questão e a influência dela sobre a historiografia alemã oitocentista, sobretudo em Ranke, ver PIRES, Francisco Murari. Ranke e Niebuhr: a apoteose tucidideana. Revista de História, n. 166, p. 80, 2012. É bom lembrar também que náo foi por outra razão que Hegel, na mesma época, diria que "esses primeiros historiadores também faziam uso de afirmaçôes e relatórios de outros" já que "é impossível que um homem possa ver tudo". HEGEL, Georg Wilhelm Friedrich. A razão na história. São Paulo: Moraes, 1990 p. 45.
} 
meiro monumentais depois estritamente documentais. Mas essas alternativas tornavam seu conhecimento ainda mais incerto e inseguro. Assim, tudo indica que o saber histórico começava a ser construído baseado na percepção da autópsia, isto é, ver/examinar por si mesmo. ${ }^{10}$ Essa prática colaborava para a distinção entre aquilo que se viu e aquilo de que se ouviu falar, traço que passou a ser essencial para alcançar a verdade das coisas ocorridas no passado.

Apesar do predomínio do "dizer" e da oralidade em relação à escrita, uma vez que se vivia ainda em uma sociedade basicamente de cultura oral, nas novas circunstâncias que começavam a se apresentar, a tendência da "escuta" era tornar-se cada vez mais secundária. O princípio do "eu ouvi", a despeito de ser ainda circunstancialmente importante em uma sociedade iletrada, gradativamente foi se tornando auxiliar à dinâmica imposta pela ação testemunhal direta e visual (eu vi) e, sobretudo, pela materialização dessa memória por meio da escrita.

Claro que as tensóes entre a escritura e a oralidade não se resolveram simplesmente ou rapidamente se dissolveram. ${ }^{11}$ Essas ambivalências entre escrita e fala, visão e audição tornaram-se centrais e permanentes na formaçấo da cultura ocidental. São bem conhecidas, por exemplo, as reflexôes de Platáo, em Fedro, ${ }^{12}$ sobre esses dilemas ao indicar certa desconfiança e conflito em relação à escrita, já que seria ela uma representação sem vida, maquinal e aparente do real. Além disso, criava uma memória artificial que, a pretexto de colaborar com e suprir a memória real, apenas ajudaria a esquecer e, como tal, transfigurava-se em uma enfermidade inimiga da verdade. ${ }^{13}$ Porém, como um pharmakón, além da qualidade de veneno, a escritura era, ao mesmo tempo e contraditoriamente, remédio eficaz contra o esquecimento, evitando a destruição do discurso. Assim, se entorpecia, a escrita também podia prestar socorro ao registrar a memória, preservar o discurso e ensinar o verdadeiro..$^{14}$

\footnotetext{
${ }^{10}$ HARTOG, François. Evidência da história. O que os historiadores veem. Belo Horizonte: Autêntica, 2011. p. $78-82$.

${ }^{11}$ As práticas mnemônicas fundamentais na cultura oral, por exemplo, sobreviveram fortemente por meio de manuais e exercícios até os séculos XV/XVI. As "artes da memória" apenas tinham sentido na sua íntima relação com a retórica e a cultura oralizada, embora pudessem também ser compreendidas como "uma espécie de escrita interior". Contudo, curiosamente, os manuais mnemônicos cuja função era treinar e desenvolver a "memória artificial" estavam fundamentalmente baseados no uso recorrente de imagens e lugares como instrumento de lembrança, e não mais na prática poética e musical, reconhecidamente muito eficazes para as rememorações. YATES, Frances. A arte da memória. Campinas: Ed. Unicamp, 2007, p. 23; RICOEUR, Paul. A memória, a história e o esquecimento, op. cit., p. 61-93.

12 PLATÁO. Fedro (Tradução do grego, Maria Cecília Gomes dos Reis). São Paulo: Penguin Classics Companhia das Letras, 2016.

${ }^{13}$ HAVELOCK, Eric. Prefácio a Platão. Campinas: Papirus, 1996, p. 20-22.

${ }^{14}$ Essa discussão das tensôes entre veneno e remédio tornou-se clássica no texto de DERRIDA, Jacques. $A$ farmácia de Platão. 2. edição. São Paulo: Iluminuras, 1997.
} 
Apesar das dúvidas e tensôes de seu tempo, a investigação e o gênero historiográfico nasciam fundados nos logos e no princípio do "eu vi". Tucídides destacou de maneira mais incisiva esse ponto, pois para ele, apesar do inquérito oral (e da escuta), o saber histórico era fundamentalmente "ver". ${ }^{15}$ Para o historiador, o binômio da retórica e da escuta não configurava procedimento confiável; a memória podia ser enganadora, e a comunicaçáo oral decorrente dela, deformadora. E o mundo das tradiçôes orais buscava simplesmente o deleite e o convencimento do ouvinte e do auditório do momento, sem compromisso em apresentar o que era verdadeiro. ${ }^{16}$ Logo, entre as duas portas dos sentidos de acesso ao conhecimento do passado (ouvir e ver), a vista (a própria e a do outro) era a mais segura, clara e verdadeira, e, no passo seguinte, desde que suas informaçôes fossem filtradas por uma crítica metódica, mais austera. ${ }^{17}$ Nessa condição, somente a escrita tornaria perenes os conhecimentos adquiridos relativos ao passado. Consequentemente, o texto alcançaria centralidade, transcendendo o próprio "feito heroico" ou o evento. Isso significava que a obra historiográfica começava a alcançar autonomia gradativa e mais relevância em relação ao autor ${ }^{18} \mathrm{e}$ até mesmo aos próprios acontecimentos narrados. Bem provavelmente esses desdobramentos colaboraram para que a obra adquirisse existência individual e duradoura para além das próprias experiências vividas (res gestae), descritas e narradas.

Tudo indica, portanto, que essa tradiçâo helênica "privilegiou em seu conjunto o visual sobre todos os outros sentidos"19 e, desse modo, estabeleceu uma espécie de fratura na historiografia ocidental ${ }^{20}$ que expôs de maneira evidente a "inferioridade do ouvido em relação à vista". ${ }^{21}$ Assim, pode-se dizer que a historiografia nasceu com uma espécie de "surdez original" e com tendência clara ao "silêncio". ${ }^{22}$ Certamente isso não ocorreu de maneira imediata. Foi

${ }^{15}$ MOMIGLIANO, Arnaldo. As raizes clássicas da historiografia moderna, op. cit., p. 70. DOSSE, François. A história. Bauru: EdUsc, 2000, p. 23.

${ }^{16}$ HARTOG, François. A evidência da história, op. cit., 2011, p. 50, 84.

${ }^{17}$ Ibidem, p. 79. Não é sem razão que historiadores do XIX como Ranke e Niebhur concederam a ele papel central na formulação de um método historiográfico e não a Heródoto. Ver PIRES, Francisco Murari. Ranke e Niebuhr: a apoteose tucidideana, op. cit.

${ }^{18}$ Aqui vale lembrar Paul Ricoeur, que afirmou que a "escrita torna o texto autônomo relativamente à intenção do autor. O que o texto significa não coincide mais com aquilo que o autor quis dizer". RICOUER, Paul. Interpretação e ideologias. 4. ed. Rio de Janeiro: Francisco Alves, 1990, p. 53.

${ }^{19}$ JAY, Martin. Ojos abatidos. Madri: Akal, 2007, p. 31.

${ }^{20}$ Vale ressaltar as vozes dissonantes que apontam outros caminhos muito interessantes de reflexão que devem ser considerados, sobretudo pelos historiadores da cultura interessados no mundo oral e aural. O antropólogo inglês Tim Ingold, por exemplo, quer discutir outros caminhos e sentidos — no seu duplo significado de interpretação e percepção (tátil, olfativa, auditiva etc.). Uma boa síntese desse debate em que procura salientar a escuta está em INGOLD, Tim. Pare, olhe, escute! Visão, audição e movimento humano. Ponto Urbe. Revista do Núcleo de Antropologia Urbana da USP, n. 3, p. 1-52, 2008. Claro que as referências culturais em que ele encontra outras maneiras de captar o mundo natural e humano - no caso específico a escuta, mas em uma percepção plurissensorial - estão nas sociedades africanas, indígenas americanas, australianas etc.

${ }^{21}$ HARTOG, François. O espelho de Heródoto, op. cit., p. 283.

${ }^{22}$ Vale aqui pequena reflexão de que sons e silêncio caminham obrigatoriamente juntos, em uma relação de presença e ausência permanente. É das oscilações dessa relação básica que aparecem as alturas, os ritmos 
preciso uma longa espera para que esse mundo silencioso da escrita e da leitura se consolidasse e as letras deixassem de ser simplesmente a indicação de um som, tornadas elementos definitivamente inscritos na linguagem visível. Paul Zumthor ocupou-se muito bem dessas questóes relativas às tensóes entre o mundo oral (ou vocal, como prefere) e da escrita durante o período medieval. ${ }^{23}$ Ele discute como, mesmo em uma sociedade oralizada/vocalizada e ruidosa, o lento processo de imposição da escrita e do olho não cessou, ainda que de maneira desigual no tempo e espaço. ${ }^{24}$ Para ele as vozes, nas suas múltiplas formulações, foram sofrendo atenuações e passando por processos civilizatórios como, por exemplo, o esforço das práticas monásticas no sentido de substituir a leitura oralizada pela silenciosa e individualizada, acompanhada da difusão relativa da escrita, ainda que manuscrita, artesanal e restrita. ${ }^{25}$ Entre os séculos XV e XVI, essas novas formas de leitura e escrita se ampliaram gradativamente, alcançando a nobreza laica, e se expandiram ainda mais e certamente com maior agilidade com o advento dos tipos móveis e da prensa. Assim, antes mesmo da verdadeira revolução cultural ocasionada pelo surgimento técnico da imprensa, já havia práticas culturais de longa duração construindo e transformando o mundo da cultura letrada e escrita. Seguramente, é possível graduar e variar mais todo esse processo de longa duração, encontrando outras situações e percepçóes, escapando da polarização, ainda que imperativa, até pelo menos o século XIX, entre o mundo oral e o da escrita. Mesmo nas mais altas camadas da cultura escrita e impressa, por exemplo,

etc. e é a partir destes elementos que as sociedades fazem suas escolhas sonoras no decorrer do tempo. Sobre o assunto, ver todo o capítulo I em WISNIK, José Miguel. O som e o sentido. São Paulo: Companhia das Letras, 1989. Desse modo, assim como pode existir uma história dos sons e ruídos, a do silêncio também deve estar no horizonte historiográfico, como entende Alain Corbin (CORBIN, Alain. Histoire du silence. De la Renaissance à nous jours. Paris: A. Michel, 2016). Para ele o silêncio não é simplesmente a ausência de ruídos, mas sobretudo uma sensibilidade interior que geralmente está nas práticas da intimidade de quartos, bibliotecas, igrejas e assim por diante. Essa "cidadela interior" construída e conquistada cotidianamente teria sofrido uma brusca ruptura na segunda metade do século XX com a "hipermedializaçáo", quando o silêncio perde espaço e seu valor cultural.

${ }^{23}$ ZUMTHOR, Paul. A letra e a voz. A literatura medieval. São Paulo: Companhia das Letras, 1993.

${ }^{24}$ Lucien Febvre, em seu estudo sobre Rabelais, disse que "Os homens daquele tempo tinham, sem dúvida, visão penetrante. Mas, precisamente, não haviam posto à parte os outros sentidos (...) o século XVI antes de ver, escutava, ouvia, cheirava o ar e captava os sons. Somente mais tarde, com a chegada do século XVII (...) foi quando se deu rédea solta à visão". FEBVRE, Lucien. O problema da incredulidade do século XVI. São Paulo: Companhia das Letras, 2009. p. 372. Em contrapartida, Johan Huizinga afirma claramente que "a característica básica do espírito medieval tardio é o seu caráter predominantemente visual (...) O pensamento se dá a partir de concepçóes visuais". HUIZINGA, Johan. Homo ludens. 7. ed. São Paulo: Perspectiva, 2012. Hoje em dia a literatura sobre o universo ruidoso desse período é bem variada e rica, para além desses autores clássicos. Apenas como referência: ALEXANDRE-BIDON, Danièle. À cor et à cri. La communication marchande dans la ville médiévale. Communications, v. 90, n. 1, p. 17-34, 2012; OFFENSTADT, Nicolas. Cris et cloches. L'expression sonore dans les rituels de paix à la fin du moyen âge. Hypothèses, n. 1, p. 51-58, 1998. GUTTON, Jean-Pierre. Bruits et sons dans notre histoire, op. cit., capítulo 1.

${ }^{25}$ ZUMTHOR, Paul. A letra e a voz, op. cit., sobretudo capítulo 5. CHARTIER, Roger. Do livro à leitura. In: CHARTIER, Roger. Práticas da leitura. São Paulo: Estação Liberdade, 2001 p. 82-83. PARKES, Malcolm. Ler, escrever, interpretar texto: práticas monásticas na Alta Idade Média. In: CAVALLO, Guglielmo; CHARTIER, Roger (Org.). História da leitura no mundo ocidental. São Paulo: Ática, 1998 p. 104-111. 
as práticas da cultura oral jamais desapareceram na suas manifestaçóes cotidianas ${ }^{26}$ ou mesmo no domínio das instituiçóes. ${ }^{27}$ Além disso, é preciso considerar também que, a partir de certo momento, esse conflito passou a representar outro tipo de oposição que se tornaria bem mais absorvente no século XIX e predominante no XX: as antinomias entre cultura primitiva e popular versus civilizada e erudita, ampliando enormemente o universo de percepçóes e tensóes culturais. Não seria demais salientar que a primeira era sempre interpretada como corporal, fragmentária e ruidosa, e a segunda, composta por contemplação, reflexão e silêncio!

Nessa extensa transferência, o ver por meio da leitura se consolidou, uma vez que a escrita teria encerrado para sempre as palavras no campo visual, e os nexos entre ler e escrever deixaram de ser "um caso particular da relação entre falar e ouvir". ${ }^{28}$ Quando a ciência moderna desenvolveu suas teorias, o olho e a visão finalmente assumiram posição central, assegurando o sentido privilegiado para transmitir de modo direto o conhecimento à "razão". ${ }^{29}$ Como se sabe, o naturalismo da ciência moderna de base cartesiana, para quem a visão era referência dos sentidos e do saber, colaborou imensamente para consagrar a cisão do conhecimento entre "espírito e matéria", cuja tendência foi alargar-se continuamente, criando como consequência um universo científico prático e profissional "surdo aos sons e insensível aos sabores e odores”, como indicou Ginzburg. ${ }^{30}$ Para a maioria dos analistas, foi esse variado conjunto que formou a base para a hegemonia "oculocentrista" do mundo moderno e estabeleceu a irremediável "tirania do olhar". 31

\footnotetext{
${ }^{26}$ As regras familiares, por exemplo, até hoje são baseadas exclusivamente em uma espécie de cultura oral. GOODY, Jack. O mito, o ritual e o oral. Petrópolis, RJ: Vozes, 2012, p. 144-145.

27 Ver WAQUET, Françoise. Parler comme un livre. L'oralité et le savoir (XVI ${ }^{\text {ème }}-X^{\text {ème }}$ siècle). Paris: AlbinMichel, 2003, p. 71. O capítulo 1 da obra fornece uma discussão teórica abrangente sobre o assunto. Roger Chartier também apresenta essa questáo dos cruzamentos do mundo oral com o da escrita presentes nos textos de teatro dos séculos XVI-XVIII. CHARTIER, Roger. Do palco à página. Publicar teatro e ler romances na Época Moderna (séculos XVI-XVIII). Rio de Janeiro: Casa da Palavra, 2002.

${ }^{28}$ RICOEUR, Paul. Interpretação e ideologias, op. cit., p. 53. Embora Barthes considere que "o homem soube escrever antes de falar". Para ele, as primeiras formas de linguagem escrita foram visuais e não originárias da fala: gestos, pictografia, traços, marcas etc. BARTHES, Roland; MARTY, Eric. Oral/escrito. In: Enciclopédia Einaudi. v. 11, Lisboa: Imprensa Nacional, 1987, p. 33.

${ }^{29}$ Casos clássicos e amplamente conhecidos nesse sentido são as teorias ópticas de Descartes e Kepler. Michel Foucault sublinhou o poder soberano desse olhar empírico e objetivante que surgia (FOUCAULT, Michel. O nascimento da clínica. Rio de Janeiro: Forense Universitária, 1997, p. XI-XIII) e que no final das contas organizou uma sociedade da vigilância, representada em última instância no século XVIII pelo panóptico de Bentham (FOUCAULT, Michel. Vigiar e punir. Petrópolis, RJ: Vozes, 1977, p. 173-199).

${ }^{30}$ A referência aqui é à física gallileana, como indicou GINZBURG, Carlo. Sinais. Raízes de um paradigma indiciário. In: GINZBURG, Carlo. Mitos, emblemas, sinais. Morfologia e história. São Paulo: Companhia das Letras, 1989, p. 158. Vale o registro de que foi nessas mesmas circunstâncias que a "história da arte" se configurou antes de mais nada como uma "história das artes visuais", colocando a pintura, as formas e a arquitetura no núcleo dela.

${ }^{31}$ Para Derrick Kerckhove, todo esse conjunto formado por escrita, leitura, olho, imprensa etc. acarretou em profundas e irreversíveis mudanças na psicologia humana que somente ocorreriam de novo com o advento da cultura eletrônica (KERCKHOVE, Derrick. A pele da cultura. Investigando a nova realidade eletrônica, op. cit., p. 47-54). Ver também JAY, Martin. Ojos abatidos, op. cit., 2007; CRARY, Jonathan. Técnicas do observador. Visão e modernidade no século XIX. Rio de Janeiro: Contraponto, 2012; MENESES, Ulpiano B.
} 
Toda essa trajetória epistemológica parece cruel para aqueles que pretendiam compreender e escutar as várias dimensões do mundo humano. Essa longa maturaçáo evidentemente ampliou a fratura original exposta na Antiguidade, opondo decisivamente o mundo da visão ao da audição, cavando ainda mais o fosso, como visto anteriormente, entre sociedades letradas, civilizadas e racionais de um lado, e oralizadas, primitivas ou populares e hiperestéticas de outro. No mundo moderno o ouvir ficou ainda mais distante. E escutar o outro se instalou, no mundo da modernidade, nas esferas da subjetividade e da memória, não mais da história. Os universos da escuta e da percepção dos sons ficaram limitados ao mundo interno da individualidade e da afetividade, ou então do prazer e da fruição. Quase nunca como elementos tangíveis para a compreensão e o entendimento do passado humano. E quando isso ocorreu, simplesmente se tornou um objeto de estudo fracionado, a ser decifrado exclusivamente pelo mundo visível. Esse padrão textual sustentado pelo ver/ler consolidou-se como mais confiável, sem dúvida por sua incrível capacidade explicativa e analítica, que colaborou significativamente para construir o mundo moderno. Ocorre que essa condição objetivadora descartou aspectos do conhecimento profundamente humanos, mas relacionados ao universo sensorial e das experiências sensíveis, afetivas e subjetivas.

Certamente é possível matizar essas dinâmicas ainda mais, já que são compostas por uma complexidade de elementos culturais de origens diversas e que apresentam no tempo múltiplos caminhos e possibilidades. Veit Erlmann, por exemplo, procura entender essa oposição aparentemente irremediável entre o mundo racional da escrita-leitura e o dos sons-subjetividade a partir de um quadro cultural mais amplo fundado em uma "história da escuta" da modernidade. E nesse enquadramento situa o interesse físico e estético pela escuta e pelos sons já na tradição racionalista moderna a partir mesmo de Descartes. Segundo esse etnomusicólogo alemão, o filósofo francês, ao se preocupar com os sentidos de modo geral, também se preocupou com as estruturas e a decodificação do som, a tal ponto que Erlmann sugere a possibilidade hiperbólica de se pensar na ideia de "Cutio ergo sum". ${ }^{32}$ Vale salientar que, no plano mais estrito da história da música, Descartes estimulou, no Compêndio da música, os estudos científicos sobre o som e a harmonia que, segundo o musicólogo italiano Enrico Fubini, contribuíram muito para o aparecimento, entre os séculos XVII-XVIII, de uma "estética musical" fundada no racionalismo. No entanto, para ele, essa raiz racionalista já podia ser encontrada nas discussóes sobre harmonia do teórico e compositor veneziano do século XVI Gioseffo Zarlino. ${ }^{33}$ Seguindo na mesma linha de tentar entender a formação de um "momento auricular", o musicólogo

de. Fontes visuais, cultura visual, história visual. Balanço provisório, propostas cautelares. Revista Brasileira de História, v. 23, n. 45, p. 12-13, 2003.

${ }^{32}$ ERLMANN, Veit. Reason and resonance. A history of modern aurality. Nova York: Zone Books, 2010; principalmente o capítulo 1.

${ }^{33}$ FUBINI, Enrico. La estética musical desde la Antiguidad hasta el siglo XX. 2. ed. Madri: Alianza Editorial, 2007, capítulo 8 . 
francês Martin Kaltenecker ${ }^{34}$ só encontrou preocupação teórica propriamente sistemática com a compreensão racional da escuta a partir de meados do século XVIII, quando se estabeleceram esforços mais organizados na construção de discursos epistemológicos sobre o tema. Para Kaltenecker, no fim daquele século é que apareceram as posturas anticartesianas contestando a supremacia óptica e ressaltando os outros sentidos, entre eles a escuta, dando início ao que denomina de "período auricular", que evoluiria intensa e rapidamente no século seguinte com o desenvolvimento científico que permitiria uma "virada auditiva". 35

Se quisermos diversificar e ampliar ainda mais um pouco a questão, é possível reconhecer que os praticantes da música, como compositores e intérpretes, sempre perceberam intuitivamente e distinguiram de maneira empírica a materialidade e os conhecimentos acústicos e físicos dos sons antes mesmo da extraordinária evolução científica que ocorre no século XIX. Os luthiers, por necessidade associada à sensibilidade, também desenvolveram uma incrível capacidade de escuta muito apurada e intuitiva para construir, por exemplo, as caixas de ressonância de seus instrumentos, antes que Helmholtz desenvolvesse suas teorias sobre o assunto e fizesse suas mediçóes das ondas oscilatórias. ${ }^{36}$ Reconheciam também como a umidade e o calor interferiam nas madeiras utilizadas nessas "caixas" e também no desempenho e na sensibilidade das cordas feitas de tripas de animais. ${ }^{37}$ Sabiam por experiência de que maneira usar a extensão e a tensão de uma corda para produzir as vibrações que emitiam onda de frequência sonora, antes que Hertz, aluno de Helmholtz, as quantificasse no final do século XIX. Claro que, a partir desse século, as diferenças e as oposiçóes entre o mundo artesanal e o da ciência, com suas invençôes e máquinas, tornaram-se mais tensas e irreconciliáveis, certamente desfavorecendo o primeiro. ${ }^{38}$

Mesmo levando em conta todas essas sinuosidades e diversidades favoráveis à percepção de um "momento auricular", o panorama insensível à escuta permaneceu na cultura oitocentista, criando obstáculos para perceber o universo sonoro como constituído de agentes ativos na esfera da percepção do mundo e do conhecimento e, consequentemente, como uma forma plausível de (re)conhecer este mundo e os homens do passado. Desse modo, essa tradição deixou de discutir se o universo sonoro poderia ser um valioso instrumento

\footnotetext{
${ }^{34}$ KALTENECKER, Martin. L'oreille divisée: discours sur l'écoute musicale aux XVIII et XIX ${ }^{\text {ème }}$ siècles. Paris: Musica Falsa, 2010. Ver, sobretudo, o capítulo 2, "L'oeil et l'oreille".

${ }^{35}$ STERNE, Jonathan. Une histoire de la modernité sonore. Paris: Ed. La Découverte, Cité de la Musique, 2015.

${ }^{36} \mathrm{Na}$ realidade, antes dele, alguns matemáticos e físicos no século XVII já se interessavam pelos fenômenos acústicos, como o religioso francês Marin Mersenne. MENEZES, Flo. A acústica musical em palavras e sons. Cotia, SP: Ateliê Editorial, 2003, p. 49-51; FUBINI, Enrico. La estética musical desde la Antiguidad hasta el siglo $X X$, op. cit.

${ }^{37}$ Esse caráter intuitivo extremado com os sons e a acústica pode ser verificado contemporaneamente, por exemplo, nas conhecidas "rabugices" de João Gilberto com luz, calor, frio excessivos nos palcos. Curioso que esses mesmos exigentes "caprichos" são tratados como normais no panorama dos solistas de violáo erudito. ${ }^{38}$ SENNETT, Richard. O artífice. Rio de Janeiro: Record, 2009; ROCHE, Daniel. História das coisas banais. Nascimento do consumo - séc. XVII-XIX. Rio de Janeiro: Rocco, 2000.
} 
cognitivo e epistemológico e até mesmo discutir a possibilidade de estabelecer uma espécie de "forma sonora de saber". ${ }^{39}$ Essa discussão, na verdade, atravessaria de maneira um tanto oculta quase todo o século XX. ${ }^{40}$

Toda essa extensa trajetória aparece de maneira dramática para os historiadores interessados na presença dos sons e das sonoridades no tempo e nas sociedades! As possibilidades de se escutar o passado e a compreensão de como os grupos humanos criaram seus sistemas de produção de sons e registros de escuta e sua recepção nunca foram considerados de maneira integral pela historiografia, uma vez que ela sempre esteve mais próxima do mundo visível que do audível e da literatura em vez dos sons, das sonoridades e dos ruídos, como salientado desde o início neste artigo. Essa condição se aprofundou principalmente com a fixação daquilo que ficou conhecido como "método histórico científico" no século XIX. Como se sabe amplamente, essa tradição historiográfica, repousada estritamente na crítica e na hermenêutica do documento escrito, ${ }^{41}$ criou uma verdadeira obsessão em torno dos registros escritos, ${ }^{42}$ "uma compulsão ou necessidade moderna e quase que predominante nas culturas chamadas ocidentais" ${ }^{43}$ Mesmo para aqueles que à época procuraram ampliar essa noção dominante de documento e do trabalho do historiador o traço visual continuou prevalecendo; ou então se avaliava que registros como lendas orais e cançôes históricas continham subjetividades excessivas, uma vez que atravessadas por imaginação e sentimento. ${ }^{44}$ Com esse "método histórico científico" emergido no século XIX houve também a inversão do caráter testemunhal, transferido definitivamente para o texto escrito, que alcançou

\footnotetext{
${ }^{39}$ ATTALI, Jacques. Bruits. Essai sur l'économie politique de la musique. Paris: PUF, 1977.

${ }^{40}$ Apesar da hegemonia do pensamento cientificista e objetivista durante a maior parte do século XX, essa questão dos aspectos cognitivos da sensibilidade sonora permaneceu viva. Ver ROEDERER, Juan. Introdução à física e psicofísica da música. São Paulo: Edusp, 2002, p. 262; SLOBODA, John A. A mente musical. A psicologia cognitiva da música. Londrina: Eduel, 2008. SACKS, Oliver. Alucinaçóes musicais. Relatos sobre a música e o cérebro. Sáo Paulo: Companhia das Letras, 2007, p. 13; LEVITIN, Daniel. A música no cérebro. Rio de Janeiro: Civilização Brasileira, 2010.

${ }^{41} \mathrm{Na}$ célebre passagem do manual de Langlois e Seignobos a "História se faz com documentos. Documentos são os traços que deixaram os pensamentos e os atos dos homens do passado (...). Ora, qualquer pensamento ou ato que não deixou traços, diretos ou indiretos, ou cujos traços visiveis desapareceram, está perdido para a história: é como nunca houvessem existido”. LANGLOIS Ch. V.; SEIGNOBOS, Ch. Introdução aos estudos históricos. São Paulo: Renascença, 1946, p. 15. (grifo nosso).

${ }^{42}$ Esse fato foi decisivo, como se sabe fartamente, para estabelecer, por exemplo, a ideia de uma "pré-história" ou definir a noção de sociedades "sem História", uma vez que "sem escrita". Curioso como essa condição se incorporou de tal modo ao "inconsciente historiográfico" que já é esquecida. Aqui vale relembrá-la, pois ela foi predominante também na formulação de uma historiografia da música, que ficou amparada estritamente na linguagem (musical) escrita e no plano especialista da estética, proporcionando uma dinâmica temporal (ou histórica) muito própria, quase que separada do mundo dos homens comuns. Já a música sem escrita ficou confinada em primeiro lugar ao universo do folclore, quando não ao "exótico", e depois ao "popular". Essa historiografia teve que esperar a revolução dos registros mecânicos e depois eletrônicos para mais tarde alcançar outro patamar de compreensão, escuta e sensibilidade, como se verá mais adiante neste texto.

${ }^{43}$ SALIBA, Elias T. Documentos, relíquias, lembranças: pequena história de aventuras e desencantos. In: KARNAL, Leandro; FREITAS NETO, José Alves (Org.). Escritas das memórias. Interpretaçôes e análises documentais. São Paulo: Instituto Cultural Banco Santos, 2004, p. 21.

${ }^{44}$ DROYSEN, Johan G. Manual de teoria da história. Petrópolis, RJ: Vozes, 2009, p. 47-48.
} 
então a dimensão de fonte exclusiva de acesso do passado e prova plena de sua verdade, desde que processado por rigoroso exame crítico externo e interno. O procedimento metódico fundado na duplicidade do logos — razão e palavra - tornou-se crucial e quase instransponível até boa parte do século XX. Tudo indica que, ao manter-se absolutamente surdo, o conhecimento histórico desconsiderou o alerta feito por Marc Bloch, algumas décadas depois, de que "poucas ciências, creio, são obrigadas a usar simultaneamente tantas ferramentas distintas" já "que os fatos humanos são mais complexos que quaisquer outros". 45

Claro que ouvir e escutar o passado nunca foram tarefas simples. Isso porque a fala, os sons e os ruídos são elementos do tempo, o que implica seu desaparecimento no ato mesmo de sua manifestação, tornando-se de certo modo intrinsecamente refratários ao registro e à escrita. Suas impressóes invadem e se assentam em primeiro lugar na memória e somente depois na linguagem e na notação, para não se perderem. Ocorre que aqueles sons e ruídos do passado que não se organizaram ou foram compreendidos na forma de música, até pelo menos meados do século XX, ficaram presos exclusivamente à memória e circunscritos a uma paisagem sonora invisível, tendendo ao silêncio e ao desaparecimento. Quase que inacessível e, consequentemente, difícil de recuperar e compreender, esse universo sonoro tornou-se avesso às historiografias, inclusive a da música, que tratou de reconsiderá-lo somente em meados do século XX. A "música iletrada” como variante da cultura oral também se manteve vinculada à memória e por isso dependente das práticas oralizadas e mnemônicas para sua preservação e difusão. Mas, diferentemente dos sons, das sonoridades e dos ruídos do cotidiano, manteve formas de sobrevivência e práticas de permanência no tempo. Foi principalmente nas relaçôes do mestre-aprendiz que conseguiu se materializar, se conservar e sobreviver. $\mathrm{O}$ aprendiz apreende a experiência do mestre observando e inicialmente "copiando" para chegar ao domínio da prática do instrumento, da voz e da expressão musical. Nessa relação vale a demonstração dos procedimentos acertados e sua memorizaçáo: ao absorver o ato correto, ele pode arquivar, reproduzir e, em seguida, recriar. ${ }^{46}$ Desse modo, há um salto qualitativo em que a imitaçáo permite o desenvolvimento do caráter musical expressivo. Essas relaçóes, como se sabe, náo ocorrem apenas de forma individualizada, uma vez que se manifestam de maneira muito corriqueira nas açôes coletivas, que desenvolvem inúmeras e criativas práticas de memorização, expressão e difusão. Nessa dimensão social, encontros, festas, celebraçóes e comemoraçôes de toda ordem são os lugares culturais centrais desse processo de práticas, formação, registro e divulgação sonora e musical.

Embora a memória também desempenhe papel determinante na música "culta" como prática mnemônica, ela é apenas subsidiária, já que "a partitura desempenha (...) o papel de

\footnotetext{
${ }^{45}$ BLOCH, Marc. Apologia da história. Ou o ofício do historiador, op. cit., p. 81.

${ }^{46}$ SENNETT, Richard. $O$ artifice, op. cit., capítulo 6.
} 
substituto do cérebro", ${ }^{47}$ o que significa tratar essa retenção como uma decorrência direta da linguagem escrita. Nesse caso, a tensão entre cultura letrada e oral volta a se manifestar, e de maneira bastante explícita. Na realidade, a notação da linguagem da música estabelece uma segunda escrita, cuja forma cria um universo próprio, muitas vezes difícil de ser aprendido e compreendido. E, como destacado logo atrás, ela expóe de modo evidente o tipo de universo sonoro que poderia se tornar história e sobre a qual a musicologia se debruçaria exclusivamente.

Mas, se a escrita registra a memória e a integralidade da autoria da criação sonora, não garante a forma de sua expressão e exposição em um tempo-espaço determinado de sua execução, sobretudo quando tenta captar as nuances das músicas sem escrita. ${ }^{48}$ Esse caráter essencialmente performático da música é mais um elemento que embaralha o trabalho da prática historiadora, pois ele recoloca em questão sua condição eminentemente transitória.

\section{Quer ver? Escuta ${ }^{49}$}

Como destacado, esse quadro começou a mudar drasticamente no último quartel do século XIX como uma das decorrências das profundas transformaçóes operadas pela "revolução científico-tecnológica”. Lentamente, o cotidiano das pessoas sofreu uma espécie de colonização microscópica e diária imposta pela tecnologia. Os grandes centros urbanos nuclearam e concentraram essas mudanças, tornando-se mais ruidosos e conflituosos do ponto de vista social, cultural e, principalmente, sonoro. Nesse novo enquadramento, campo se opôs à cidade, tradição à modernidade e natureza às máquinas. Aliás, as máquinas, e suas derivaçôes, tornaram-se definitivamente o espelho desse novo mundo. E um dos aspectos proeminentes nesse quadro foi exatamente o desenvolvimento da tecnologia sonora e seus aparelhos, muito embora o mundo visual, com o incremento da fotografia e do cinema, tenha se ampliado ainda mais, favorecendo a visão. ${ }^{50}$ De qualquer modo, é nesse novo ambiente científico e tecnológico que aparece um conjunto de dispositivos que iria mudar drastica-

\footnotetext{
${ }^{47}$ HALBWACHS, Maurice. Memória coletiva dos músicos. In: HALBWACHS, Maurice. A memória coletiva. São Paulo: Vértice, 1977, p. 165.

${ }^{48}$ Harnoncourt discute essa questão relacionada à música anterior ao século XIX, quando a notação não era muito clara e rigorosa, mas, sobretudo, porque antes daquele século havia regras não escritas de desempenho e o espaço para o improviso era recorrente. HARNONCOURT, Nicolas. O discurso dos sons. Caminhos para uma nova compreensão musical. Rio de Janeiro: Jorge Zahar, 1998; ver especialmente o capítulo "Problemas de notação", p. 34-48. Mas, bem antes do maestro austríaco, Mário de Andrade colocou de maneira notável a problemática quando destacou que "os maxixes impressos de Sinhô são no geral banalidades melódicas. Executados, são peças soberbas (...)”. (ANDRADE, Mário de. Ensaio sobre a música brasileira. São Paulo: Livraria Martins Editora, 1962, p. 23.

${ }^{49}$ ALVIM, Francisco. Poema de Francisco Alvim (1938). In: ALVIM, Francisco. Poemas (1968-2000). São Paulo: Cosac Naify; Rio de Janeiro: 7 Letras, 2004, p. 55.

${ }^{50}$ CRARY, Jonathan. Técnicas do observador. Visão e modernidade no século XIX, op. cit., 2012.
} 
mente a relação das pessoas com os sons e sua difusão: o telefone, o fonógrafo e, mais tarde, o rádio. Bem provavelmente por essas razóes, a bibliografia sobre o tema durante muito tempo sempre destacou a centralidade e os êxitos triunfais dos aspectos tecnológicos, dando-lhes quase vida própria autônoma, que impulsionariam dali em diante a vida humana. Veremos logo a seguir que as interpretações sobre o assunto mudaram significativamente. ${ }^{51}$

Alguns autores, como Sterne e Steege, ampliam esses horizontes de interesses para além do cotidiano e discutem como, à época, havia uma preocupação mais dilatada e científica com o universo auricular e acústico. Ela estaria presente, por exemplo, nas experiências acústicas de Helmhotz ${ }^{52}$ e nas de Thomas Edison, mas também nas novas práticas diagnósticas da medicina baseadas no estetoscópio e na auscultação, assim como também no telégrafo, o primeiro sistema de comunicação elétrica ponto a ponto. A instrumentalização da razão e da ciência estimulava a codificação e a racionalização do que se escutava e, ao mesmo tempo, ampliava suas fronteiras sociais e culturais. ${ }^{53}$ Segundo esses autores, este quadro poderia apontar para um reequilíbrio entre as percepçóes seculares e hegemônicas visuais da modernidade e a de escuta do mundo, o que parece ter ocorrido apenas parcialmente. Mas o que interessa do ponto de vista dessa discussão é que esses aparelhos produziram pelo menos dois vetores de mudanças profundas: nas sensibilidades de escuta sonora e das práticas musicais, e nos seus registros reproduzíveis, questóes que deveriam obter algum interesse direto da historiografia contemporânea. Certamente, são problemáticas que estão intimamente relacionadas, uma vez que a capacidade de registro impóe transformaçóes radicais na sensibilidade e nas possibilidades e práticas de escuta. $\mathrm{O}$ registro, por exemplo, permitiu que os ouvintes fossem transportados dos recintos públicos, das salas de concerto, do entretenimento ou dos espaços comunitários para a exclusividade e a atenção da atmosfera doméstica. Nesse ambiente de imediato ocorre o distanciamento evidente entre artistas e assistência, mas talvez não entre criação e recepção. Além disso, a multiplicação dos cilindros/discos permitia a simultaneidade e a repetição de escutas. Esses são dois fatores que indicariam a perda da aurabilidade da obra e de sua prática performática única, situação reclamada por críticos do período uma vez que apontavam para a massificação da arte. Em contrapartida, houve uma incrível possibilidade de aproximação ao material sonoro, já que ele poderia ser repetido infinitas vezes, em lugares diferen-

\footnotetext{
${ }^{51}$ Geralmente a bibliografia sobre o assunto destaca a centralidade e os êxitos triunfais dos aspectos tecnológicos. Friedrich Kittler tem uma postura interessante sobre o tema, pois procura associar as posturas histórica, da materialidade e a sistêmica (KITTLER, Friedrich. Gramophone, film, tupewritter. Stanford: SUP, 1999). Ou seja, as tecnologias e as mídias formam sistemas materiais que se relacionam intimamente com as práticas e os discursos sociais sobre elas. Assim, seus conteúdos são imanentes à materialidade dos suportes por onde se manifestam. Além de conceder autonomia ao ouvido e à escuta, tais suportes são também meios de registro e notação, para além da escrita, tornando-se esteios para a memória cultural, condição que nos interessa nas discussões deste artigo.

52 STEEGE, Benjamin. Helmhotz and the modern listener. Cambridge: Cambridge University Press, 2012.

${ }^{53}$ STERNE, Jonathan. Une histoire de la modernité sonore, op. cit., 2015.
} 
tes, liberando milhares de possibilidades de escuta, retirando de criadores, especialistas e críticos a possibilidade de apenas uma única escuta "real e verdadeira". ${ }^{54}$ Essas mudanças sem dúvida foram cruciais e determinaram o novo regime de escuta no século XX, ou sua audiabilidade.

Contudo, não se pode creditar apenas às alterações tecnológicas e suas máquinas maravilhosas as profundas transformações que ocorriam no período. As mudanças tiveram caráter bem mais amplo, como registrado logo atrás, e certamente estão também relacionadas com a produção de uma "cultura de massas" que, para muitos historiadores, é anterior à midiática e suas formas de circulação e recepção. ${ }^{55}$ Neste ponto, percebe-se a complexidade social e cultural do processo, pois a difusão e a apropriação exigem antes outra percepção de tempo e seu uso tanto coletivo como individual. Na sociedade urbana e industrial, elas estão vinculadas às novas práticas e regras de sociabilidade advindas do mundo do trabalho, mas sobretudo dos usos do tempo livre e das novas formas de entretenimento. Nesse sentido, aparece o lazer doméstico como elemento importante, mas sobrelevam as inúmeras formas de entretenimentos que surgem e passam a ser oferecidas diariamente às centenas nas grandes cidades, fato que implicou também a conquista do tempo noturno. ${ }^{56} \mathrm{~A}$ música nesses espaços e nessas práticas alcançou gradativamente papel relevante que máquinas e equipamentos ampliaram significativamente. E, afinal, todo esse conjunto criou as condiçóes culturais, sociais e técnicas que possibilitaram a reorganização de uma economia da música até então muito precária, quase inexistente. ${ }^{57}$ Esses foram índices importantes, sem os quais a "música em conserva" ${ }^{58}$ certamente não teria condiçóes de evoluir do ponto de vista social

\footnotetext{
${ }^{54}$ Umberto Eco discutiu essas questóes de maneira precursora em seu conhecido artigo "La musique et la machine" (ECO, Umberto. La musique et la machine. Comunication, n. 6, 1965). Nele, discute a amplitude das transformaçôes que ocorreram com a escuta mediada pelas máquinas que certamente alcançaram também a música erudita, para horror dos críticos e analistas da época. Ele recrimina os críticos da "música em conserva" que não entenderam esse novo mundo cultural. O debate deve ser compreendido também nos limites da discussão em que ele opóe "apocalípticos e integrados". Curioso como a literatura mais atual sobre o assunto e de tradição anglosaxônica "silencia" quase completamente esse artigo e as posições de Eco.

${ }_{55}$ Ver sobre o assunto, ROCHE, Daniel. História das coisas banais. Nascimento do consumo - séc. XVIIXIX, op. cit., 2000; RIOUX, Jean-Pierre; SIRINELLI, Jean-François. La culture de masse em France. De la Belle Époque à aujourd'hui. Paris: Fayard, 2002.

${ }^{56}$ Painel interessantíssimo sobre esses aspectos está em CORBIN, Alain (Org.). História dos tempos livres. Lisboa: Teorema, 2001. Ver também RAUCH, André. Les usages du temps libre. In: RIOUX, Jean-Pierre; SIRINELLI, Jean-François. La culture de masse em France. De la Belle Époque à aujourd'hui, op. cit., 2002, p. 353-408; TOURNĖS, Ludovic. Le temps maîtrisé: l'enregistrement sonore et les mutations de la sensibilité musicale. Vingtième Siècle. Revue d'histoire, Paris, Presses de la Fondation Nationale des Sciences Politiques, p. 5-15, 2006. Adorno também discute essa questáo do tempo livre e do lazer nos limites da indústria cultural. Ao contrário do simples divertimento, ela produziria atitudes passivas e comportamentos conformistas, gerando alienação. (ADORNO, Theodor. Tempo livre. In: ADORNO, Theodor. Palavras e sinais. Petrópolis, RJ: Vozes, 1995).

${ }^{57}$ TOURNES, Ludovic. Reproduirel'oeuvre: la nouvelle économie musicale. In: RIOUX, Jean-Pierre; SIRINELLI, Jean-François. La culture de masse em France. De la Belle Époque à aujourd'hui, op. cit., 2002, p. 258-220.

${ }^{58}$ Esse era um modo popular para designar, entre o final do século XIX e início do XX, o arquivamento dos sons
} 
e cultural. É por isso que a historiadora Sophie Maisonneuve afirma sinteticamente que essa nova cultura é

uma invenção complexa e coletiva, onde o objeto se inventa conjuntamente com as suas práticas, onde o mercado é criado juntamente com a mídia e seus usos. É por essa tripla inovação [técnica, comercial e cultural] que o disco e a escuta hedonista doméstica da música tornaram-se o que são hoje: tanto transparentes quanto onipresentes na cultura cotidiana. ${ }^{59}$

Claro que esse processo não ocorre do dia para a noite. Os estranhamentos e os incômodos, inclusive os de aspectos legais e de direito, ${ }^{60}$ com os aparelhos e as tecnologias eram constantes e permaneceram até pelo menos a década de 1930. De acordo com a historiografia, nesse período ocorreram novas transformações que impulsionaram definitivamente esse universo. A historiografia identifica o desenvolvimento da gravação elétrica como central e a melhoria das condições e práticas nos estúdios, na medida em que elas aperfeiçoaram significativamente os registros sonoros, ${ }^{61}$ aprimorando, consequentemente, as escutas. Nesse novo horizonte se discute como elas ensejaram um registro e uma escuta mais fiéis às performances originais, aparecendo daí a noção de fidelidade e depois de "alta fidelidade", que se expandiria no período pós-guerra. ${ }^{62}$ Além disso, houve o barateamento das chapas e dos aparelhos, expandindo as possibilidades de difusão e de escuta. Mas é preciso considerar, sobretudo, que os novos gêneros musicais urbanos voltados e conformados para o disco e as gravaçôes (que ficariam conhecidos como "música popular") estavam se decantando e ficando prontos para uma divulgação massiva. Nesse turbilhão de transformaçóes, a radiofonia acaba por assumir papel central, ocupando o lugar da cultura fonográfica. No entanto, se nos seus primórdios essas duas formas de difusão da música foram encaradas como concorrentes, elas rapidamente se associaram e o binômio disco-rádio consolidou finalmente esse universo sonoro e musical em construção desde o século XIX. Nesse ambiente, a música erudita tentou resistir, distanciar-se, embora já

\footnotetext{
e das músicas nos cilindros de pianola e, sobretudo, nos fonográficos de cera. Claro que a forma dos invólucros colaborava para criar a imagem da música "enlatada". Logo depois, ela serviu também para nomear as chapas e os discos fonográficos, mas que rapidamente se transformaram nas "esferas negras".

${ }^{59}$ MAISONNEUVE, Sophie. De la machine parlante au disque - une innovation technique, commercial et culturelle. Vingtième Siècle. Revue d'Histoire, v. 4, n. 92, p. 31, 2006.

${ }^{60}$ Ver SZENDY, Peter. Ecouté. Une histoire de nos oreilles, op. cit., capítulo 3.

${ }^{61}$ IAZZETTA, Fernando. Música e mediação tecnológica. São Paulo: Perspectiva, 2009, principalmente o capítulo 4 .

${ }^{62}$ Sobre "fidelidade" e "alta fidelidade", ver STERNE, Jonathan. Une histoire de la modernité sonore, op. cit., capítulo 5. MAISONNEUVE Sophie. L'invention du disque (1877-1949). Genése de l'usage des médias musicaux contemporains. Paris: Archives Comteporaines, 2009, p. 172-82. IAZZETTA, Fernando. Música e mediação tecnológica, op. cit., capítulos 9 e 11.
} 
estivesse completamente atravessada por esse universo, mesmo fazendo ouvidos surdos a essa situação. ${ }^{63}$

Nessas circunstâncias aparecem novos atores sociais, para além da formalidade da música de concerto e da informalidade quase sempre cerimoniosa da música coletiva de origem rural. Audiófilos e amadores escutavam, guardavam, colecionavam e falavam sobre música, retirando a prática musical do plano exclusivo dos especialistas e artistas. ${ }^{64}$ Mais ruidosos, "fonófilos, fonômanos e discômanos" participavam ao seu modo e ativamente do universo da "música mecânica". Todos eles tratavam de "tocar" seus aparelhos: rapidamente "tocar um disco" passou a ser equivalente a "tocar música" ${ }^{65} \mathrm{O}$ ouvinte tornava-se assim executor e regente, dando início à configuração daquilo que Peter Szendy denominaria de ouvintes-músicos. ${ }^{66}$ Apesar da autonomia relativa, certo é que essas escutas também eram profundamente direcionadas pelas indústrias fonográficas, radiofônicas e a imprensa especializada derivada delas, uma vez que estava em jogo a formação de um novo gosto e de um novo e extraordinário mercado. Mas para que este se constituísse, essas peças culturais e sociais deveriam estar acomodadas ou se encaixando de algum modo.

Artistas e intelectuais não ficaram indiferentes a esse novo panorama, seja para compreendê-lo, incorporá-lo ou criticá-lo profundamente. Repleto de complexidades e nuances, os diagnósticos acerca desse cenário e das escutas contemporâneas produziram análises e reflexões profundamente distintas. Pierre Schaeffer, por exemplo, compreendeu que o universo sonoro era bem mais amplo que o musical e, portanto, sua escuta poderia ser bem mais extensa. Em primeiro lugar, sons e ruídos de toda ordem deveriam ser incluídos, uma vez que se multiplicaram enormemente e estavam em toda parte na ordem cultural moderna. Além disso, os novos dispositivos de gravação e mediação sonora proporcionaram o surgimento de novos sons que não eram mais os da natureza, da voz humana ou de instrumentos tradicionais. Como "sinal dos tempos" em que vivia, Schaeffer procurou entender as questóes técnicas e estéticas presentes na radiofonia e no cinema, para compreender a nova arte ruidosa que surgia. ${ }^{67}$ Nesse conjunto amplo, destacou e considerou a "orelha como instrumento" fundamental para as escutas no mundo moderno. Como estas eram carregadas de subjetividades, identificou e formulou uma pequena tipologia de escuta: acusmática, banal, prática, cultural, natural, direta,

\footnotetext{
${ }^{63}$ Nesse sentido, o trabalho de Maisonneuve é muito interessante, pois ela descortina as relaçôes da indústria fonográfica e da nova sensibilidade e escuta musical na música erudita, enquanto a maior parte dos trabalhos sobre o assunto se refere quase que exclusivamente à música popular. MAISONNEUVE, Sophie. L'invention du disque (1877-1949). Genése de l'usage des médias musicaux contemporains, op. cit.

${ }^{64}$ MAISONNEUVE, Sophie. La constituition d'une culture et d'une écoute musicale nouvelles. Revue de Musicologie, t. 88, n. 1, , p. 43-66, 2002; MAISONNEUVE, Sophie. De la machine parlante à l'auditeur. Revue Terrain, p. 11-28, 2001.

${ }^{65}$ IAZZETTA, Fernando. Música e mediação tecnológica, op. cit., sobretudo o capítulo 1.

${ }^{66}$ SZENDY, Peter. Ecouté. Une histoire de nos oreilles, op. cit.

${ }^{67}$ SCHAEFFER, Pierre. Ensaio sobre o rádio e o cinema. Estética e técnica das artes relé (1941-42). Belo Horizonte: EdUFMG, 2010 p. 29.
} 
reduzida etc. ${ }^{68}$ Mas foi Adorno quem apresentou pela primeira vez, do ponto de vista teórico e de modo sistemático, uma reflexão sobre a "escuta". Suas análises nessa direção têm início no final dos anos 1930 e, como se sabe, a referência mais abrangente era a teoria crítica geral da moderna sociedade tecnológica que produzia a homogeneização da cultura por meio da indústria cultural. Nesses limites, ela teria criado a ilusão de "que os meios mecânicos e de massa teriam levado pela primeira vez a música a um número incontável de indivíduos". ${ }^{69}$ Adorno projetou examinar o comportamento musical e a recepçáo dos ouvintes neste novo contexto, tensionado entre o universo estético musical interno e as determinaçốes da sociedade de massas. Esse longo processo de maturação o arrastou mais tarde à sistematização de uma tipologia das escutas. Sua preocupação com o ouvinte contemporâneo o levou à identificação de alguns tipos de escuta: a do expert, do bom ouvintelamateur, do consumidor, do emocional, do ressentimento/estático, do fã (de jazz), do entretenimento e do indiferente. Embora crítico de todos esses tipos, já que buscava uma escuta perfeita e desalienada, suas posturas deixam transparecer evidente hierarquizaçáo nos vários tipos de ouvintes, que variam em uma ponta da "escuta estrutural", melhor e mais informada do que as outras; à outra ponta, a do entretenimento, recusada integralmente por ele. Mais do que participar da verdadeira aporia da época entre a "melhor" e a "pior" escuta/música, o que evidenciam essas discussóes é o vivo interesse em destacar a emergência de novas práticas e novos comportamentos de escuta, de suas redes de sociabilidade e de como se revelam e interferem no mundo de modo cada vez mais presente e evidente. E seus registros, bem ou mal, deixaram de simplesmente se dissipar, uma vez que a possibilidade de serem rastreados por meio da "música em conserva" tornou-se real, mesmo que difícil e complexa.

\section{Escutar os mortos}

Nesse contexto, reaparece o outro aspecto a respeito da "música em conserva" que interessa também discutir e remete ao debate inicial: sua função de registro, sonoro neste caso específico, e de construção de outra memória externa para além da escrita, até então apenas ilusória e inexequível. Assim retomamos a questão historiográfica central desta introdução exposta desde o início: a escrita e o registro da memória. Nesse sentido, nunca é demais recordar que as palavras fonógrafo e depois gramofone se referem diretamente à escrita, à letra, à grafia e ao registro da voz e do som. E que a primeira função do fonógrafo era substituir a dupla papel-escrita e facilitar oralmente a comunicaçáo e o registro administrativo de empresas. Logo, seu sentido estava relacionado intimamente ao mundo da escrita, mas, como se sabe, com o tempo

\footnotetext{
${ }^{68}$ SCHAEFFER, Pierre. Traité des objets musicaux; essai interdisciplines. Paris: Seuil, 1966 p. 204. O autor faz uma pequena tipologia estabelecendo a escuta acusmática, a indireta, a direta, a reduzida etc.

${ }^{69}$ ADORNO, Theodor. Introdução à sociologia da música, op. cit., p. 56.
} 
ele se ampliou enormemente, causando uma profunda mudança cultural, da qual alguns dos aspectos se procura discutir nesse texto. ${ }^{70}$ Pois bem, se antes do aparecimento desses aparelhos sonoros só se podia "escutar os mortos com os olhos", ${ }^{71}$ com o registro nos cilindros e depois nos discos tornou-se possível escutar diretamente os vivos e, sobretudo, os mortos, com os ouvidos! ${ }^{12}$ Essa problemática foi identificada no momento mesmo de expansão da técnica e dos aparelhos sonoros. Freud, por exemplo, avaliou que os gramofones conservavam as "transitórias impressóes sonoras do homem" e que eram também "materializaçôes de sua faculdade de lembrar, de sua memória”. ${ }^{73}$ Mesmo Adorno, com sua conhecida antipatia ao disco, reconheceu sua utilidade (aliás, para ele a única àquela época) para preservar e difundir a música, mesmo que "amputada da sua melhor dimensão" ${ }^{74}$ É que o aparecimento e a rápida evolução dos sons gravados mecanicamente e depois eletronicamente mudou completamente a antiga dinâmica das escutas. As novas formas de criação, memorização, registro, divulgação e reprodução de sons e da música construíram e expandiram um novo e incrível universo composto de sonoridades, escutas, técnicas e sociabilidades, para além do conhecimento da linguagem musical e das habilidades do executante. E, nessas novas condiçôes, os fonogramas apareceram como portas valiosas e mais acessíveis para os historiadores chegarem aos sons organizados do passado.

Apesar das naturais resistências iniciais, gradativamente o fonograma tornou-se indício importante para investigaçóes e práticas relacionadas à memória e ao passado. Entre o final do século XIX e o início do XX, a antropologia foi a primeira a utilizá-lo, ainda que de forma assistemática e quase sempre no sentido salvacionista da memória de culturas agonizantes e da preservação delas e seus sons. Seus registros "passaram, de certa forma, a representar para as músicas ágrafas o que os acervos de manuscritos representavam para música erudita do século XIX" ${ }^{75} \mathrm{Na}$ Europa, a preocupação com a organização de expediçôes científicas para captar os sons da vida campesina interna do continente ou então das comunidades existentes

\footnotetext{
${ }^{70}$ A esse respeito, Derrida diz sobre a fonografia que essa "conjunção da cibernética e das 'ciências humanas' da escritura conduz a uma subversão mais profunda” (DERRIDA, Jacques. Gramatologia, op. cit., p. 12).

${ }^{71}$ Roger Chartier, citando poema de Quevedo (CHARTIER, Roger. Escutar os mortos com os olhos. Estudos avançados, v. 24, n. 69, 2010, p. 7.

${ }^{72}$ Aliás, o conhecido símbolo da RCA-Victor, que consagrou a imagem do cachorro Nipper na corneta do gramofone, revela exatamente essa situação. A voz que ele escuta e reconhece é "voz do seu mestre" falecido, o gravurista e pintor Mark Henry Barraud. Sterne discute esse curioso papel dos registros sonoros para dar vida à "voz do defunto". Foi comum durante certa época, no início do século XX, a apresentação de gramofones nos velórios soando a voz do falecido, funcionando como uma espécie de embalsamento sonoro (STERNE, Jonathan. Une histoire de la modernité sonore, op. cit. Ver capítulo 6, "Tumba ressoante").

${ }^{73}$ FREUD, Sigmund. O mal-estar da civilização. In: FREUD, Sigmund. Obras completas. São Paulo: Companhia das Letras, 2001, p. 33.

${ }^{74}$ ADORNO, Theodor. La forme du disque. In: ADORNO, Theodor. Beaux passages. Écouter la musique, op. cit., p. 222.

${ }_{75}$ ARAÚJO, Samuel. Característica e papéis dos acervos etnomusicológicos em perspectiva histórica. In: ARAÚJO, Samuel; PAZ, Gaspar; CAMBRIA, Vincenzo (Org.). Música em debate. Perspectivas interdisciplinares. Rio de Janeiro: Mauad, 2008, p. 43.
} 
nas colônias africanas aparece já no final do século XIX. O desdobramento visível e concreto delas foi o aparecimento dos primeiros arquivos sonoros, seja da palavra ou da música. ${ }^{76}$ No continente americano, naturalmente elas se dirigiram sobretudo à escuta, ao registro e à preservação das culturas indígenas e, posteriormente, trataram de incorporar também as manifestaçóes folclóricas. ${ }^{77}$ Foi precisamente assim que ocorreu no Brasil: no início do século XX, apareceram missóes e atitudes preservacionistas como as dos alemães Wilhelm Kissenberth e Koch-Grunberg, e de Roquette-Pinto, direcionadas exclusivamente às populaçôes indígenas. Mais tarde, as campanhas de Mário de Andrade e Luiz Heitor de Oliveira se dirigiram ao "mundo do folclore" e acabaram gerando importantes acervos fonográficos.

De maneira assimétrica, a indústria fonográfica desempenhava outro tipo de papel cultural. Na verdade, ela surgiu sem nenhuma pretensão educativa ou cultural formal. Seu objetivo era vender os produtos, inicialmente apenas os aparelhos reprodutores: fonógrafos, depois gramofones. Rapidamente ela identificou a necessidade de integrar aparelho e cilindro/ disco, desenvolvendo um ativo mercado fonográfico cujo centro era gravar aquilo adequado ao "gosto popular" e que podia ser rapidamente vendido. Desse modo, ela realiza a busca e o registro das culturas musicais presentes nos centros urbanos. Mais tarde, a associaçáo com a radiofonia tornou esse processo irrefreável. Além de acolher e colaborar para decantar os gêneros urbanos em desenvolvimento e divulgá-los em proporçóes jamais vistas, o binômio rádio-disco criou e tratou de conservar e consolidar a memória das "músicas populares urbanas". Ocorre que a historiografia raramente se preocupou com essa incrível e desconcertante dinâmica cultural. Em primeiro lugar, certamente porque as práticas historiográficas das primeiras décadas do século XX, voltadas preferencialmente para um passado mais distante, criavam enormes dificuldades para compreender as rápidas mudanças que esse conjunto operava naquele tempo presente. Além disso, suas características eram muito ruidosas, embaralhando um universo cultural razoavelmente estável, produzindo assim tensóes naturais,

\footnotetext{
${ }^{76}$ Considera-se o arquivo de Viena, fundado em 1899, como a primeira instituiçáo dedicada ao registro sonoro. Um ano depois foram fundados os de Berlim e de Paris, seguidos por muitos outros a partir dos anos 1920. Inicialmente, eles nascem com preocupação de registro da palavra e da língua, somente posteriormente música e cançóes ocupam espaço, a tal ponto que alguns deles se tornam, com o tempo, arquivos musicais. LUDOVIC, Tournès. L'enregistrement sonore et les mutations de la sensibilité musicale. Vingtienne Siècle. Revue d'Histoire, n. 92, p. 5-15, 2006; CORDEREIX, Pascal. Les enregistrement du musée de la parole et du geste à l'expostion coloniale. Entre science, propagande et commerce. Vingtienne Siècle. Revue d'Histoire, n. 92, p. 47-59, 2006. VERDURE, Nicolas. Les archives de l'enregistrement sonore à la bibliothèque nationale de France. Vingtienne Siècle. Revue d'Histoire, n. 92, p. 1-66, 2006. No Brasil, a primeira discoteca foi concebida por Mário de Andrade em 1935, assim que assumiu a direção do Departamento de Cultura da cidade de Sáo Paulo. A Discoteca Municipal ganhou corpo e densidade quando tratou de produzir o próprio acervo com o projeto da Missáo Folclórica de 1937-1938. Atualmente, ela funciona no Centro Cultural de São Paulo com o nome de Discoteca Oneyda Alvarenga.

77 Além das populaçôes autóctones, nos Estados Unidos surgem também projetos para captar e registrar as músicas dos cowboys e dos bluesmen, realizados por John Lomax e depois por seu filho Alan Lomax. STERNE, Jonathan. Une histoire de la modernité sonore, op. cit., 2015, p. 444-476. Alguns dos registros feitos por ele podem ser consultados em <http://research.culturalequity.org/home-audio.jsp >.
} 
imprecaçóes e, por fim, preconceitos de toda ordem contra uma cultura vinculada à multidão. E, certamente, o milenar "regime de silêncio" e a hegemonia do texto escrito contribuíram enormemente para a constituição de uma espécie de "gap historiográfico". ${ }^{78}$ Nesse ponto, novamente as tradiçôes da cultura científica historiográfica foram decisivas para a conhecida e persistente ausência dos registros de sons e músicas, sobretudo "a iletrada", nos arquivos e acervos, e certamente como objeto da história.

Apesar de a incrível cultura fonográfica ter apresentado uma nova "época de escuta" que apontou, segundo alguns autores, para uma espécie de "giro auditivo", 79 a historiografia permaneceu ausente, acentuando a surdez orginal dos historiadores. Se para o historiador nunca foi fácil penetrar no universo desconhecido dos sons e da linguagem musical específica, uma vez que esta última exigia dele especializaçôes muito estritas, na passagem para o século XX essa condição começou a se alterar. Com a "música em conserva" e a evolução da cultura fonográfica a questão da escuta musical deixou de ser uma habilidade apenas para iniciados e para aqueles com talento raro. A ideia de que "todo membro de nossa sociedade é capaz de ouvir e, portanto, de entender música" 80 não só alterou uma condição social e cultural importante, como também abriu para os historiadores da cultura um estupendo campo de pesquisa que necessariamente impunha uma nova postura teórico-metodológica para sua incorporação e seu tratamento. No entanto, esse território de conhecimento em formação teve que aguardar a longínqua entrada dos anos 1990 e a chegada do século XXI, quando, finalmente, "a surdez dos historiadores [apresentou uma] via de cura". ${ }^{81}$ Certamente houve uma série de elementos convergentes para esse sucesso. $O$ primeiro deles sem dúvida foram as transformaçóes internas ocorridas na "oficina da história" nas décadas anteriores, já amplamente conhecidas e debatidas. A musicologia, de seu lado, tratou de ampliar seus horizontes, apontou novos caminhos e, percorrendo alguns deles, tentou se aproximar da história social. A etnomusicologia também diversificou enormemente seus temas e seus objetos, perdendo a simpatia exagerada pela "música primitiva" ou "rural", e ingressando em outros universos sonoros e teóricos. Seu diálogo com a antropologia sonora foi fundamental para sua ampliação, confundindo-se muitas vezes com ela. Ao mesmo tempo, a antropologia desenvolveu um campo das sensibilidades ou das percepçóes em que as paisagens e os

\footnotetext{
${ }^{78}$ Jean-Pierre Rioux e Jean-François Sirinelli utilizam a ideia de "gap historiográfico" para indicar que a historiografia, de modo geral, nunca se preocupou com as realidades da cultura de massas. Eles reclamam que esse preconceito produziu um "gap historiográfico" até pelo menos os anos 1980, quando seus temas e objetos começaram a ser dignos de estudos acadêmicos. Acrescentamos de modo mais enfático que isso ocorreu principalmente com a música produzida nesse sistema, que ficou conhecida como "música popular". RIOUX, Jean-Pierre; SIRINELLI, Jean-François. La culture de masse em France. De la Belle Époque à aujourd'hui, op. cit. Ver introdução.

${ }^{79}$ GAUTIER, Ana Maria Ochoa. Aurality. Listening and Knowledge in Nineteenth Century Colombia. Durham: Duke University Press, 2014. p. 1-29. Introduction: The ear and the voice.

${ }^{80}$ LEVITIN, Daniel. A música no seu cérebro, op. cit., 2007, p. 291.

${ }^{81}$ CHIMÈNES, Myriam. Musicologie et histoire. Frontière ou "no man's land" entre deux disciplines. Revue de Musicologie, Société Française de Musicologie, t. 84, n. 1, p. 78, 1998.
} 
territórios sonoros, humanos e naturais assumiram papel importante. ${ }^{82}$ Nesse horizonte, ela ususfruiu muito das discussóes musicológicas em torno da noção de "paisagem sonora". ${ }^{83} \mathrm{Na}$ esteira desse interesse crescente em diversos campos do conhecimento, ${ }^{84}$ surgiu até mesmo uma indefinida e insegura "musicologia da música popular" que durante certo tempo buscou reconhecimento acadêmico e disciplinar. ${ }^{85}$ Os chamados "estudos culturais" desenvolveram reflexóes e estudos (sobre temas como juventude, gênero, subculturas, contraculturas etc.) que colaboraram direta e indiretamente para o desenvolvimento dessa nova "musicologia”. E, bem mais recentemente, os sound studies se apresentaram como uma nova ferramenta interdisciplinar que tem os sons e o que as culturas fazem com eles como objeto central. ${ }^{86}$ O que ocorre é que muitas vezes esses contatos geraram tensóes com a historiografia, uma vez que algumas dessas áreas — seja por convicção epistemológica e/ou por necessidade de consolidar um novo campo de saber disciplinar e acadêmico — procuravam ou ainda procuram estabelecer regras metodológicas rígidas ou construir estatutos científicos fortes, ao passo que a história já há algum tempo está mais preocupada em apresentar caminhos mais alternativos baseados em certo "rigor flexível", como sugeriu Ginzburg. ${ }^{87}$

De qualquer modo, para sarar a "surdez milenar" historiográfica foi determinante "escutar os mortos" para além do registro escrito (musical ou literário). Os fonogramas tornaram-se instrumentos valiosos para o historiador interessado nos sons e na música. E a tal ponto que, curiosamente, certas linhas investigativas passaram a valorizar excessivamente o fonograma, tratando-o muitas vezes com aquela perspectiva oitocentista de uma janela objetiva aberta para o passado. Ocorre que as músicas contidas neles acionam uma série infinita de dispositivos e sentidos culturais, que passam por sua criação, produção e recepção contemporânea, sua escuta futura que é também a do historiador. Além do que, como suportes

${ }^{82}$ Uma introdução da discussão sobre essa viragem do sensível pode ser consultada em HOWES, David; MARCOUX, Jean-Sébastien. Introduction à la culture sensible. Anthropologie et sociétés, v. 30, n. 3, p. 7-17, 2006. Mais estritamente relacionado aos aspectos sonoros, ver um bom painel atual em CANDAU, Joel; GONIDEC, Marie-Barbara (Dir.). Paysages sensoriels. Essai d'anthropologie de la construction et de la perception de l'environnement sonore. France: CTHS, 2013.

${ }^{83}$ SCHAFER, Murray. O ouvido pensante. São Paulo: Unesp, 1991.

${ }^{84}$ Como, por exemplo, o trabalho do músico Bernie Krause, que, baseado também na noção de paisagem sonora, em uma perspectiva, digamos, mais ambientalista, desenvolveu uma incrível pesquisa e um acervo de registro sonoro da natureza. Ver: <http://www.wildsanctuary.com/>. Uma amostra do que ele tem feito pode ser verificada na obra KRAUSE, Bernie. A grande orquestra da natureza. Descobrindo as origens da música no mundo selvagem. Rio de Janeiro: Zahar, 2013, e em <http://www.legrandorchestredesanimaux.com/br>, além de outros registros nas redes digitais.

${ }^{85}$ Ver, por exemplo, GONZÁLEZ, Juan Pablo. Musicologia popular en América Latina: sintesis de sus logros, problemas y desafíos. Revista Musical Chilena, ano 55, n. 195, p. 38-58, jan./jun. 2001.

${ }^{86}$ Ver STERNE, Jonathan. "Sound Studies", une nouvelle discipline?. Notes de Passage. Le magazine en ligne de la Citè de la Musique, entrevista, 10/09/2015; BULL; Michel; LES BACK (Ed.). Introduction: into sound. In: BULL, Michel; LES BACK. The auditory culture reader. Nova York: Berg, 2003, p. 1-18; GAUTIER, Ana Maria Ochoa. Aurality. Listening and Knowledge in Nineteenth-Century Colombia, op. cit.

${ }^{87}$ GINZBURG, Carlo. Mitos, emblemas, sinais. Morfologia e história, op. cit., p. 179. 
concretos de acesso dos sons e da música, eles são também indícios da circulação musical e devem se tornar eles mesmos objetos de pesquisa. ${ }^{88}$ Se é possível identificar sua trajetória física e quantitativa, muito embora costumeiramente as informaçóes discográficas sejam sempre muito mais precárias que as bibliográficas, rastrear e entender os atos de escuta é um processo bem mais difícil e complexo. Nicholas Cook chega a afirmar que somente no ato da escuta a gravaçáo pode revelar os sinais do acontecimento social e musical, alterando o sentido de "realidade espelhada" como muitas vezes são encarados discos e gravaçóes. ${ }^{89}$ Para ele o significado das escutas dos fonogramas é instável e mutável, marcado pelas circunstâncias culturais em que são ouvidos lá no passado e aqui no presente. Certamente essas questóes apontadas pelo musicólogo inglês são bem importantes, mas não devem causar impacto e estranheza a uma boa parte dos historiadores que cuida de suas fontes sem as ilusóes corriqueiras e sabe das instabilidades e multiplicidades de formas de sentir e entender o mundo e suas coisas. De modo geral, o historiador da cultura reconhece já há certo tempo que é preciso estabelecer relações entre o valor e a análise interna da obra (a criação, o foco tradicional da história da música, p. ex.), com as histórias do suporte físico que as mantém (partituras, instrumentos, disco, rádio etc.), que supóem e determinam inúmeras dinâmicas culturais e práticas sociais (tanto as individuais como as coletivas), que se manifestam em um universo imenso de locais e redes (ruas, salas de concertos, festas, teatros etc.). E, finalmente, o elemento mais complicado de se identificar e analisar: as infinitas possibilidades de recepção (as escutas) que se apresentam nessa complexa trama sonora.

Se no período dos registros fonográficos escutar os mortos se tornou mais viável, como se procurou discutir tanto do ponto de vista teórico como da prática historiadora, permanecem ainda indagaçóes e dúvidas sobre as maneiras de escutá-los quando esses registros nunca existiram, ou seja, antes da "virada auditiva" do final século XIX ou nos milhares de situações cotidianas ou de espetáculo sem quaisquer interesses de inscrição fonográfica. Ou quando e onde eles deixaram de existir por aquelas centenas de razóes que fazem os rastros desaparecerem parcial ou completamente no tempo. Reaparecem assim dois elementos cruciais da discussão em torno das formas de acessar esse passado sonoro e musical: as problemáticas e os limites da "memória sonora evanescente" e da "silenciada", e as evidentes limitações oferecidas pela linguagem musical e também fonográfica para penetrar nesse mundo. Aproximar-se do panorama de sons e práticas de escutas que não ascenderam ao universo formal da estética musical, seja por meio da partitura ou no fonograma, continua sendo um

\footnotetext{
${ }^{88}$ KATZ, Mark. Capturing sound: how technology has changed music. Berkeley: University of California Press, 2004.

${ }^{89}$ COOK, Nicholas. Methods for analysing recordings. In: COOK, Nicholas; CLARKE, Eric; LEECHWILKINSON, Daniel; RINK, John (Ed.). The Cambridge Companion to Recorded Music. Cambridge: Cambridge University Press, 2009 p. 223-245. Vale a lembrança de que Nicholas Cook criou um importante centro de referência do "mundo do disco" no Center for the History and Analysis of Recorded Music (Charm). Cf. www.charm.rhul.ac.uk.
} 
caminho intricado e complexo. O roteiro operacional mais comum sempre foi tratar com os registros escritos indiretos, sejam eles quais forem, que falam dos sons e ruídos ou comentam sobre música. Eles seriam centrais para alcançar e compreender certos pensamentos e escutas musicais de uma época e também para se aproximar das sonoridades ali produzidas e difundidas. Para o historiador da cultura essa indicação não apresenta novidade, uma vez que ela é determinante no trabalho metódico do historiador nesse território instável, repleto de armadilhas e rastros traiçoeiros, cujas informações, percepçóes e discursos têm caráter renitente que teimam em não se revelar facilmente.

Nesse horizonte repleto de embaraços e incertezas, o historiador é obrigado a usar ao mesmo tempo a imaginação histórica e construir certa sensibilidade para perceber e retirar do registro escrito um mundo sonoro ali silencioso, uma vez que náo se escuta nele a estridência dos ruídos, a altura da fala, o volume do som, o barulho do vento, o grito da multidão ou do vizinho, a beleza da voz do cantor, o instrumento desafinado e assim por diante. Isso requer um mergulho vertical profundo no mundo da cultura da época investigada para compreender e alcançar essas camadas sonoras e fazê-las ressoar novamente de algum modo. ${ }^{90}$ Delimitar o universo e o perfil dessas fontes, em uma imensidão de experiências culturais e sonoras fragmentadas e opacas, para validá-las em uma compreensão e narrativa que dê sentido à "beleza do morto", ${ }^{11}$ não é tarefa simples. Ainda mais porque, como indicado desde o início, a historiografia sempre foi ligeiramente surda para ajudar nos quadros mais gerais de referência teórica e historiográfica. ${ }^{92}$ Certamente os trabalhos de história cultural podem colaborar muito para ajudar a encontrar caminhos nessa direção, sobretudo aqueles que, desde a década de 1980, se preocuparam com as culturas populares de modo geral. ${ }^{93}$ Bem mais recentemente surgiram investigações e discussôes centradas es-

${ }^{90}$ Atualmente os recursos tecnológicos viabilizaram enormemente uma aproximação das experiências sonoras do passado, possibilitando conhecer um pouco mais da "beleza do morto". O passeio sonoro e visual no projeto multimidiático coordenado por Daniel Roche e produzido pela musicóloga Mylène Pardoen (<https://lejournal.cnrs.fr/articles/ecoutez-le-paris-du-xviiie-siecle>) revela de maneira extraordinária essas possibilidades. E no sentido do mergulho da imaginação histórica trabalhando em favor da escuta do morto, ver o capítulo "Cabaré eletrônico". Cançóes de rua de Paris, em 1748-50, e sua respectiva página web. In: DARTON, Robert. Poesia e polícia. Sáo Paulo: Companhia das Letras, 2014.

${ }^{91}$ CERTEAU, Michel de. A beleza do morto. In: CERTEAU, Michel de. A cultura no plural. 6. ed. São Paulo: Papirus, 2010. O texto traça um panorama geral e crítico do debate entre os historiadores em meados do século XX em torno da cultura popular. Certeau areja profundamente a discussão que se concentrava em interpretaçóes reducionistas como: a pureza e originalidade da cultura popular; ou sua submissão e opressão à cultura formal; ou sua condição de resistência à cultura dominante.

${ }^{92}$ FARGE, Arlette. Essai pour une histoire des voix aux $18^{\text {eme }}$ siècle. Montrouge: Bayard, 2009, p. 10 e p. $107-$ 108 para passagem anterior.

${ }^{93}$ As discussóes sobre o assunto são relativamente antigas e muito variadas, não cabendo aqui alongar demasiadamente o assunto. Apenas registrar que os trabalhos historiográficos sobre o tema começaram a se multiplicar nos anos 1960 (REVEL, Jacques. Cultura popular: usos e abusos de uma ferramenta historiográfica. In: REVEL, Jacques. Proposiçôes. Ensaios de história e historiografia. Rio de Janeiro: Eduerj, 2009) e a tal ponto que, durante a década de 1980, Michel Vovelle afirmou que "o popular está em moda, sem nenhuma intenção pejorativa, pois há modas boas" (VOVELLE, Michel. Ideologias e mentalidades. São 
tritamente no panorama sonoro que colaboraram para sonorizar pelo menos parcialmente esses caminhos. ${ }^{94} \mathrm{E}$ como desdobramento dessas preocupaçóes e referências, as discussóes em torno de certa história das sensibilidades e/ou das emoções bem provavelmente podem ajudar, uma vez que elas ampliam nossa compreensão da percepção do mundo e ajudam a entender a presença e o papel da auralidade, da oralidade, da vocalidade e da musicalidade no mundo social. E também porque a documentação que nos dá ingresso ao mundo sonoro geralmente está marcada por emoçóes e critérios de sensibilidades e subjetividade muito evidentes. ${ }^{95}$

Seja qual for o caminho escolhido nesse amplo território sonoro que a historiografia da cultura procura entender neste ruidoso início do século XXI, a colaboração interdisciplinar é um imperativo permanente para a compreensão e construção do conhecimento do passado, como se procurou discutir. Ademais, neste universo, a operação historiográfica comporta elementos imponderáveis e "pouco científicos [como] faro, golpe de vista, intuição" 96 — e certamente a escuta!

\section{Referências bibliográficas}

ADORNO, Theodor. Beaux passages. Écouter la musique. Paris: Payot, 2013. . Introdução à sociologia da música. São Paulo: Unesp, 2011. . Palavras e sinais. Petrópolis, RJ: Vozes, 1995.

Paulo: Brasiliense, 1987, p. 153), mas para Jacques Revel tornou-se uma moda “das mais cansativas". REVEL, Jacques. A invenção da sociedade. Lisboa: Difel; Rio de Janeiro: Bertrand, 1989, p. 45).

${ }^{94}$ Apenas como referência recente, DARTON, Robert. Poesia e polícia, op. cit. FARGE, Arlette. Essai pour

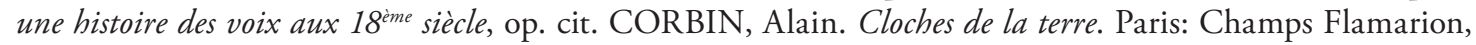
1994. No Brasil a partir da década de 1990 houve um evidente interesse e crescimento das pesquisas acadêmicas estritamente no campo da história, interessadas pela música, sobretudo a popular. Um painel e um balanço desta nova dinâmica do final do século XX podem ser verificados na pesquisa História e Música na Universidade, que produziu um banco de dados sobre o tema que pode ser acessado em <http:// www.memoriadamusica.com.br/site/index.php/historia-e-musica-na-universidades, e no artigo do bolsista SOARES NETO, Raul Celestino de. Cadência brasileira: decompondo os acordes da historiografia da música no Brasil. Revista Ars Historica, n. 7, p. 152-168, jan./jun. 2014. Disponível em: <www.historia.ufrj.br/ ars/>. Especificamente sobre os aspectos sonoros mais amplos, para além da música, os trabalhos acadêmicos são muito raros, valendo a lembrança de APROBATO FILHO, Nelson. Kaleidosfone. As novas camadas sonoras da cidade de São Paulo (fins do séc. XIX e início do XX). São Paulo: Edusp, 2008.

${ }^{95}$ Ver CORBIN, Alain. Histoire et antropologie sensorielle. Anthropologie et sociétés, v. 14, n. 2, p. 13-24, 1990; JAY, Martin. No reino dos sentidos: uma introdução. Urbana, Ciec/Unicamp, v. 4, n. 5, p. 3-11, dez. 2012. HOWES, David; MARCOUX, Jean-Sébastien. Introduction à la culture sensible. Anthropologie et sociétés, v. 30, n. 3, p. 7-17, 2006. DELUERMOZ, Quentin; FUREIX, Emmanuel; MAZUREL Hervé; OUALDI M'hamed. Écrire l'histoire des émotions: de l'objet à la catégorie d'analyse. Revue d'Histoire du XIXe siècle, n. 47, p. 155-180, 2013.

${ }^{96}$ GINZBURG, Carlo. Mitos, emblemas, sinais. Morfologia e história, op. cit. 
ALEXANDRE-BIDON. Danièle. À cor et à cri. La communication marchande dans la ville médiévale. Communications, v. 90, n. 1, p. 17-34, 2012.

ALVIM, Francisco. Poema de Francisco Alvim (1938). In: ALVIM, Francisco. Poemas (1968-2000). São Paulo: Cosac Naify; Rio de Janeiro: 7 Letras, 2004, p. 55.

AMBROISE-RENDU, Anne Claude; DEMARTINI, Anne-Emmanuelle; ECK, Hélène; EDELMAN, Nicole. (Dir.). Émotions contemporaines XIX-XXI siècles. Paris: Armand Colin, 2014.

ANDRADE, Mário de. Ensaio sobre a música brasileira. São Paulo: Livraria Martins Editora, 1962 , p. 23.

APROBATO FILHO, Nelson. Kaleidosfone. As novas camadas sonoras da cidade de São Paulo (fins do séc. XIX e início do XX). São Paulo: Edusp, 2008.

ARAÚJO, Samuel. Característica e papéis dos acervos etnomusicológicos em perspectiva histórica. In: ARAÚJO, Samuel; PAZ, Gaspar; CAMBRIA, Vincenzo (Org.). Música em debate. Perspectivas interdisciplinares. Rio de Janeiro: Mauad, 2008, p. 43.

ATTALI, Jacques. Bruits. Essai sur l'économie politique de la musique. Paris: PUF, 1977.

BARTHES, Roland; MARTY, Eric. Oral/escrito. In: Enciclopédia Einaudi. Lisboa: Imprensa Nacional, 1987, p. 33. v. 11.

BLOCH, Marc. Apologia da história. Ou o ofício do historiador. Rio de Janeiro: Jorge Zahar, 2001. p. 81.

BULL, Michel; LES BACK (Ed.). The auditory culture reader. Nova York: Berg, 2003.

CANDAU, Joel; GONIDEC, Marie-Barbara (Dir.). Paysages senroriels. Essai d'anthropologie de la construction et de la perception de l'environnement sonore. Paris: CTHS, 2013.

CERTEAU Michel de. A cultura no plural. 6. ed. São Paulo: Papirus, 2010.

CHARTIER, Roger. Práticas da leitura. São Paulo: Estação Liberdade, 2001.

- Do palco à página. Publicar teatro e ler romances na época moderna (séculos XVIXVIII). Rio de Janeiro: Casa da Palavra, 2002.

CHARTIER, Roger; CAVALLO, Guglielmo (Org.). História da leitura no mundo ocidental. São Paulo: Ática, 1998.

CORBIN, Alain. Histoire du silence. De la Renaissance à nous jours. Paris: A. Michel, 2016. . Histoire et antropologie sensorielle. Anthropologie et sociétés, v. 14, n. 2, p. 13-24, 1990.

. Cloches de la terre. Paris: Champs Flamarion, 1994.

. Histoire et antropologie sensorielle. Anthropologie et sociétés, v. 14, n. 2, 1990.

COOK, Nicholas. Methods for analysing recordings. In: COOK, Nicholas; CLARKE, Eric; LEECH-WILKINSON, Daniel; RINK, John (Ed.). The Cambridge Companion to Recorded Music. Cambridge: Cambridge University Press, 2009, p. 223-245. 
CRARY, Jonathan. Técnicas do observador. Visão e modernidade no século XIX. Rio de Janeiro: Contraponto, 2012.

DARTON, Robert. Poesia e polícia. São Paulo: Companhia das Letras, 2014.

DELUERMOZ, Quentin; FUREIX, Emmanuel; MAZUREL Hervé; OUALDI, M’hamed. Écrire l'histoire des émotions: de l'objet à la catégorie d'analyse. Revue d'Histoire du XIXe siècle, n. 47, p. 155-180, 2013.

DERRIDA, Jacques. A farmácia de Platão. 2. ed. São Paulo: Iluminuras, 1997. . Gramatologia. São Paulo: Perspectiva, 1973, p. 12.

DOSSE, François. A história. Bauru: Edusc, 2000, p. 23.

DROYSEN, Johan G. Manual de teoria da história. Petrópolis, RJ: Vozes, 2009, p. 47-48.

ECO, Umberto. La musique et la machine. Comunication, n. 6, 1965.

ERLMANN, Veit. Reason and Resonance. A History of Modern Aurality. Nova York: Zone Books, 2010.

FARGE, Arlette. Essai pour une histoire des voix au 18 ime siècle. Montrouge: Bayard, 2009.

FEBVRE, Lucien. O problema da incredulidade do século XVI. São Paulo: Companhia das Letras, 2009, p. 372.

FOUCAULT, Michel. O nascimento da clínica. Rio de Janeiro: Forense Universitária, 1997, p. XI-XIII.

. Vigiar e punir. Petrópolis, RJ: Vozes, 1977, p. 173-199.

FREUD, Sigmund. O mal-estar da civilização. In: FREUD, Sigmund. Obras completas. São Paulo: Companhia das Letras, 2001, p. 33.

FUBINI, Enrico. La estética musical desde la Antiguidad hasta el siglo XX. 2. ed. Madri: Alianza Editorial, 2007.

GAUTIER, Ana Maria Ochoa. Aurality. Listening and Knowledge in Nineteenth-Century Colombia. Durham: Duke University Press, 2014.

GINZBURG, Carlo. Sinais. Raízes de um paradigma indiciário. In: GINZBURG, Carlo. Mitos, emblemas, sinais. Morfologia e história. São Paulo: Companhia das Letras, 1989.

GONZÁlEZ, Juan Pablo. Musicologia popular en América Latina: sintesis de sus logros, problemas y desafíos. Revista Musical Chilena, ano 55, n. 195, p. 38-58, jan./ jun. 2001.

GOODY, Jack. O mito, o ritual e o oral. Petrópolis, RJ: Vozes, 2012, p. 144-145.

GUTTON, Jean-Pierre. Bruits et sons dans notre histoire. Paris: PUF, 2000.

HALBWACHS, Maurice. Memória coletiva dos músicos. In: HALBWACHS, Maurice. $A$ memória coletiva. São Paulo: Vértice, 1977, p. 165. 
HARNONCOURT, Nicolas. $O$ discurso dos sons. Caminhos para uma nova compreensão musical. Rio de Janeiro: Jorge Zahar, 1998.

HARTOG, François, Evidência da história. O que os historiadores veem. Belo Horizonte: Autêntica, 2011.

. O espelho de Heródoto. Belo Horizonte: UFMG, 1999.

HAVELOCK, Eric. A revolução da escrita na Grécia. São Paulo: Unesp/Paz e Terra, 1996, p. 21.

. Prefácio a Platão. Campinas: Papirus, 1996, p. 20-22.

HEGEL, Georg Wilhelm Friedrich. A razão na história. São Paulo: Moraes, 1990, p. 45.

HERÁCLITO DE EFESO. In: Pré-socráticos. Os Pensadores. v. 1. São Paulo: Nova Cultural. p. 61.

HOWES, David; MARCOUX, Jean-Sébastien. Introduction à la culture sensible. Anthropologie et sociétés, v. 30, n. 3, p. 7-17, 2006.

HUIZINGA, Johan. Homo ludens. 7. ed. São Paulo: Perspectiva, 2012.

IAZZETTA, Fernando. Música e mediação tecnológica. São Paulo: Perspectiva, 2009.

INGOLD, Tim. Cultura, percepção e ambiente. Diálogos com Tim Ingold. Ponto Urbe. São Paulo: Terceiro Nome, 2012.

. Pare, olhe, escute! Visão, audição e movimento humano. Ponto Urbe. Revista do Núcleo de Antropologia Urbana da USP, n. 3, p. 1-52, 2008.

JAY, Martin. No reino dos sentidos: uma introdução. Urbana, Ciec/Unicamp, v. 4, n. 5, p. 3-11, dez. 2012.

. Ojos abatidos. Madri: Akal, 2007.

KALTENECKER, Martin. L'oreille divisée: discours sur l'écoute musicale aux XVIII et XIX $^{\text {ème }}$ siécles. Paris: Musica Falsa, 2010.

KERCKHOVE, Derrick. A pele da cultura. Investigando a nova realidade eletrônica. São Paulo: Annablume, 2009.

KITTLER, Friedrich. Gramophone, flm, typewritter. Stanford: SUP, 1999.

LANGLOIS Ch. V.; SEIGNOBOS, Ch. Introdução aos estudos históricos. São Paulo: Renascença, 1946, p. 15.

KRAUSE, Bernie. A grande orquestra da natureza. Descobrindo as origens da música no mundo selvagem. Rio de Janeiro: Zahar, 2013.

LEVITIN, Daniel. A música no seu cérebro. Rio de Janeiro: Civilização Brasileira, 2010.

MAISONNEUVE, Sophie. De la machine parlante au disque - une innovation technique, commercial et culturelle. Vingtième Siècle. Revue d'Histoire, v. 4, n. 92, p. 31, 2006. 
. De la machine parlante à l'auditeur. Revue Terrain, p. 11-28, 2001.

La constituition d'une culture et d'une écoute musicale nouvelles. Revue de Musicologie, t. 88, n. 1, p. 43-66, 2002.

. Linvention du disque (1877-1949). Genése de l'usage des médias musicaux contemporains. Paris: Archives Comteporaines, 2009.

MÉIER, Christian. Antiguidade. In: KOSSELECK, Reinhart (Org.). O conceito de história. Belo Horizonte: Autêntica, 2013, p. 43.

MENESES, Ulpiano B. de. Fontes visuais, cultura visual, história visual. Balanço provisório, propostas cautelares. Revista Brasileira de História, v. 23, n. 45, p. 12-13, 2003.

MENEZES, Flo. A acústica musical em palavras e sons. Cotia, SP: Ateliê Editorial, 2003, p. 49-51.

MERLEAU-PONTY, Maurice. Fenomenologia da percepção. 2. ed. São Paulo: Martins Fontes, 1999.

MOMIGLIANO, Arnaldo. As raizes clássicas da historiografia moderna. Bauru: Edusc, p. 59-66.

OFFENSTADT, Nicolas. Cris et cloches. L'expression sonore dans les rituels de paix à la fin du moyen âge. Hypothèses, n. 1, p. 51-58, 1998.

PARKES, Malcolm. Ler, escrever, interpretar texto: práticas monásticas na Alta Idade Média. In: CAVALLO, Guglielmo; CHARTIER, Roger (Org.). História da leitura no mundo ocidental. São Paulo: Ática, 1998, p. 104-111.

PIRES, Francisco Murari. Ranke e Niebuhr: a apoteose tucidideana. Revista de História, n. 166, p. 80, 2012.

PLATÃO. Fedro. Tradução do grego de Maria Cecília Gomes dos Reis. São Paulo: Penguin Classics Companhia das Letras, 2016.

RAUCH, André. Les usages du temps libre. In: RIOUX, Jean-Pierre; SIRINELLI, JeanFrançois. La culture de masse em France. De la Belle Époque à aujourd'hui. Paris: Fayard, 2002, p. 353-408.

REVEL, Jacques. A invenção da sociedade. Lisboa: Difel; Rio de Janeiro: Bertrand, 1989, p. 45.

. Cultura popular: usos e abusos de uma ferramenta historiográfica. In: REVEL, Jacques. Proposiçôes. Ensaios de história e historiografia. Rio de Janeiro: Eduerj, 2009.

RICOEUR, Paul. A memória, a história e o esquecimento. Campinas: Ed. Unicamp, 2007. . Interpretação e ideologias. 4. ed. Rio de Janeiro: Francisco Alves, 1990, p. 53.

RIOUX, Jean-Pierre; SIRINELLI, Jean-François. La culture de masse en France. De la Belle Époque à aujourd'hui. Paris: Fayard, 2002. 
ROCHE, Daniel. História das coisas banais. Nascimento do consumo - séc. XVII-XIX. Rio de Janeiro: Rocco, 2000.

ROEDERER, Juan. Introdução à física e psicofísica da música. São Paulo: Edusp, 2002, p. 262.

SACKS, Oliver. Alucinaçôes musicais. Relatos sobre a música e o cérebro. São Paulo: Companhia das Letras, 2007, p. 13.

SALIBA, Elias T. Documentos, relíquias, lembranças: pequena história de aventuras e desencantos. In: KARNAL, Leandro; FREITAS NETO, José Alves (Org.). Escritas das memórias. Interpretaçóes e análises documentais. São Paulo: Instituto Cultural Banco Santos, 2004, p. 21.

SCHAFER, Murray. O ouvido pensante. São Paulo: Unesp, 1991.

SCHAEFFER, Pierre. Ensaio sobre o rádio e o cinema. Estética e técnica das artes relé (194142). Belo Horizonte: EdUFMG, 2010, p. 29.

. Traité des objets musicaux; essai interdisciplines. Paris: Seuil, 1966.

SENNETT, Richard. O artifice. Rio de Janeiro: Record, 2009.

SLOBODA, John A. A mente musical. A psicologia cognitiva da música. Londrina: Eduel, 2008.

SOARES NETO, Raul Celestino de Toledo. Cadência brasileira: decompondo os acordes da historiografia da música no Brasil. Revista Ars Historica, n. 7, p. 152-168, jan./jun. 2014. Disponível em: <www.historia.ufrj.br/-ars/>.

STEEGE, Benjamin. Helmhotz and the modern listener. Cambridge: Cambridge University Press, 2012.

STERNE, Jonathan. Une histoire de la modernité sonore. Paris: Ed. La Découverte, Cité de la Musique, 2015.

SVENBRO, Jesper. A Grécia arcaica e clássica: a invenção da leitura silenciosa. In: CAVALLO, Guglielmo; CHARTIER, Roger (Org.). História da leitura no mundo ocidental. São Paulo: Ática, 1998, p. 50-57.

SZENDY, Peter. Ecouté. Une histoire de nos oreilles. Paris: Ed. de Minuit, 2001.

TUCIDIDES, História da Guerra do Peloponeso. Tradução do grego de Mário da Gama Kury. 4. ed. Brasília: Editora Universidade de Brasília, Instituto de Pesquisa de Relações Internacionais; São Paulo: Imprensa Oficial do Estado de São Paulo, 2001. I. 22, p. 14.

TOURNÈS, Ludovic. Le temps maîtrisé: l'enregistrement sonore et les mutations de la sensibilité musicale. Vingtième Siècle. Revue d'histoire, Paris, Presses de la Fondation Nationale des Sciences Politiques, p. 5-15, 2006.

. Reproduire l'oeuvre: la nouvelle économie musicale. In: RIOUX, Jean-Pierre; SIRINELLI, Jean-François. La culture de masse em France. De la Belle Époque à aujourd'hui. Paris: Fayard, 2002, p. 258-220 
VOVELLE, Michel. Ideologias e mentalidades. São Paulo: Brasiliense, 1987, p. 153.

ZUMTHOR, Paul. A letra e a voz. A literatura medieval. São Paulo: Companhia das Letras, 1993.

WAQUET, Françoise. Parler comme un livre. L'oralité et le savoir (XVI ${ }^{\text {ème}-X X}{ }^{\text {ème }}$ siècle). Paris: Albin-Michel, 2003.

WISNIK, José Miguel. O som e o sentido. São Paulo: Companhia das Letras, 1989.

YATES, Frances. A arte da memória. Campinas: Ed. Unicamp, 2007, p. 23.

\section{Como citar:}

MORAES, José Geraldo. Escutar os mortos com os ouvidos. Dilemas historiográficos: os sons, as escutas e a música. Topoi. Revista de História, Rio de Janeiro, v. 19, n. 38, p. 109139, mai./ago. 2018. Disponível em: <www.revistatopoi.org>. 